\title{
The link between flipped and active learning: $a$ scoping review
}

\section{Rita Li, Andreas Lund \& Anita Nordsteien}

To cite this article: Rita Li, Andreas Lund \& Anita Nordsteien (2021): The link between flipped and active learning: a scoping review, Teaching in Higher Education, DOI: 10.1080/13562517.2021.1943655

To link to this article: https://doi.org/10.1080/13562517.2021.1943655

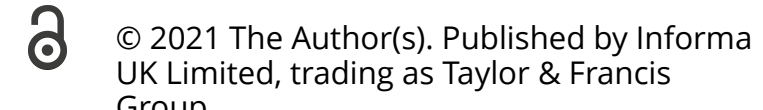
Group

进 Published online: 20 Jun 2021.

Submit your article to this journal $\sqsubset$

Q View related articles $\square$

View Crossmark data $\complement \pi$ 


\title{
The link between flipped and active learning: a scoping review
}

\author{
Rita $\mathrm{Li}^{\mathrm{a}}$, Andreas Lund $\mathrm{BD}^{\mathrm{b}}$ and Anita Nordsteien (D) \\ ${ }^{a}$ Department of Education and Quality in Learning, University of South-Eastern Norway, Kongsberg, Norway; \\ ${ }^{b}$ Department of Teacher Education and School Research, University of Oslo; 'Department of Optometry, \\ Radiography and Lighting Design, University of South-Eastern Norway, Kongsberg, Norway
}

\begin{abstract}
Flipped learning in higher education is becoming increasingly widespread. Although the number of flipped learning articles has increased since 2011, systematic reviews of flipped learning have been criticized for lacking a theoretical framework. The aim in this article is to explore the link between flipped learning and active learning: specifically, which theoretical frameworks are described. A scoping review was adopted as the research methodology. The selected studies indicate that this link between flipped learning and active learning is rarely explicitly addressed or operationalized. Approximately $65 \%$ of the 435 full-text articles retrieved do not explicitly connect their research to theory or a conceptual framework. The remaining 155 studies included for analysis refer to a mix of pedagogical terms or approaches. The theoretical and conceptual underpinnings are generally only vaguely described, with a few exceptions. The results indicate an eclecticism and a reluctance to connect flipped learning with a specific conceptual framework.
\end{abstract}

\section{ARTICLE HISTORY}

Received 1 October 2020

Accepted 8 June 2021

\section{KEYWORDS}

Flipped classroom; flipped learning; inverted learning; active learning; higher education

\section{Introduction}

Technology and digitalization have brought about tremendous changes in classroom practices, compelling the academic world to think beyond the traditional style of mono-directional teaching and learning as acquisition or even consumption and reproduction (Lundin et al. 2018; Sfard 1998). One of the latest indications of such change is the idea - and broader acceptance - of flipped learning (FL) (Cheng, Ritzhaupt, and Antonenko 2019; Muldrow 2013). FL in higher education is becoming increasingly widespread as a new and innovative learning approach stemming from the pedagogical concept of active learning (Yang, Lin, and Hwang 2019). Although some of the practices of FL, also called 'inverted learning' (Lage, Platt, and Treglia 2000), have been in use for decades, in recent years it has been widely adopted by educators at all levels of education and across many disciplines (Gayathri and Vijayarani 2017; Steen-Utheim and Foldnes 2018; Yang, Lin, and Hwang 2019). 
The increased traction and implementation of FL in higher education may be explained by focused efforts to help students reach higher cognitive levels in their learning processes; increase student engagement; create a paradigm shift from teacher-centred to student-centred learning; help students develop lifelong learning skills; and ensure the development of skills desired by employers (e.g. 'twenty-firstcentury skills', which include critical thinking, collaboration and self-direction) (Framework for twenty-first Century Learning 2010; Overmyer 2015). In addition, higher education institutions are now receiving a new generation of students, the millennials, who were born between 1982 and 2002. These students are used to 24/7 connectivity and access, and the ability to capture, process, send and receive information through multiple devices - anytime, anywhere (Alario-Hoyos et al. 2019; Howe and Strauss 2003).

While there has been a significant increase in the literature on FL since 2011 (Lundin et al. 2018; Yang, Lin, and Hwang 2019), the field is still at an early stage, as many articles report results from first attempts at using FL (Låg and Sæle 2019). The design and methods of FL can vary widely from class to class, but a fundamental principle lies in the name: the structure of learning is flipped upside down, pushing passive learning out of the classroom while pulling in active learning during the time previously used for lectures. While this working definition captures the justification for using the terminology 'flipped', it also underlines the active learning component, as FL involves more than just shifting content delivery outside of class time (Bishop and Verleger 2013). The entire classroom experience is built around active learning experiences: here, understood as meaningful learning of educational objectives, not merely 'being active'. As there is a substantial body of literature related to the concept of active learning (Drake 2012), this provides indirect support for the utilization of FL.

Active learning was one of the two most frequently used keywords according to an analysis of the keywords of 149 articles about FL from 2000 to 2015 (Yang, Lin, and Hwang 2019). Recent systematic reviews have identified a variety of theoretical frameworks for FL e.g. personalization, higher-order thinking, self-direction, collaboration, problem-based learning, peer assisted learning, cognitive load theory and self-determination (Bishop and Verleger 2013; Cheng, Ritzhaupt, and Antonenko 2019; Koh 2019; Seery 2015). These conceptual frameworks typically argue for the positive impact of active learning and have strong theoretical underpinnings in constructivism. However, few studies have examined how active learning theories guide the development and evaluation of the flipped approach to learning (Abeysekera and Dawson 2015; Koh 2019).

Despite FL being widely adopted in higher education, systematic reviews of FL have been criticized for lacking a theoretical framework (Abeysekera and Dawson 2015). There is a call for stronger pedagogical theorization of its practice, and the need to establish a robust framework on how FL is implemented (Bishop and Verleger 2013; Koh 2019; Lundin et al. 2018; O'Flaherty and Phillips 2015; Seery 2015). Thus, this scoping review addresses the empirical literature on FL through the lens of active learning to help provide theoretical underpinnings for FL. We now examine the many conceptualizations and definitions of FL that provide a pedagogical framework; our aim in doing so is to amplify the understanding of FL, of which active learning is an important element. 


\section{Defining flipped learning}

In the empirical literature, we find extensive variety in how FL is defined: for example, some underline the usage of digital technology while others focus on collaborative learning or group learning activities (Låg and Sæle 2019). Among its many definitions, FL is referred to as a pedagogical approach, instructional approach, teaching approach, learning technique, educational strategy, method, student-centred approach, active learning methodology, instructional model, active learning design, didactic methodology, hybrid teaching, active learning technique and holistic pedagogic scaffold (Ahmed 2016; Cheng, Ritzhaupt, and Antonenko 2019; Harris and Welch Bacon 2019; Koh 2019; Lin and Hwang 2019; Seery 2015; Yang, Lin, and Hwang 2019). Despite the lack of a universal definition of FL, the active learning component remains a common theme across the definitions used in FL research. For many years, educators have assumed - and also experienced - that active learning environments are generally more effective in students' learning processes than passive, lecture-dominated learning environments (Abeysekera and Dawson 2015; Prince 2004). FL restructures and reorders traditional lecture-based (LB) approaches by moving students, rather than teachers, to the centre of learning. In her classic article, 'From Sage on the Stage to Guide on the Side', King (1993) stresses the importance of the use of class time for the construction of meaning, rather than just the transmission of facts. King's early work is a momentum for an inversion in the classroom, from the traditional lecture-based approach to giving students time to engage in active learning. Research on active learning has shown that it contributes to student learning, achievement and engagement (Chaplin 2009; Freeman et al. 2007; Hake 1998; Knight and Wood 2005; Prince 2004). Thus, if FL leads to active learning, does the current evidence allow us to draw the conclusion that FL contributes to increased student learning?

From the literature reviews, we are still left with a rather opaque picture regarding the benefits of FL (Evans et al. 2019; Låg and Sæle 2019). The studies also largely lack anchoring in e.g. learning theory, and many contain methodological weaknesses (Evans et al. 2019; Lundin et al. 2018). Abeysekera and Dawson (2015) claim that the FL approach is 'under-evaluated, under-theorized and under-researched in general'. In a scoping review, O'Flaherty and Phillips (2015) identified several gaps in the literature that need to be addressed for effective implementation of FL in the curriculum transformation by educators. These include the underutilization of theoretical frameworks that enable a joint approach to pre-, face-to-face and post-learning activities - which in turn can result in heavy content focus and a lack of clarity.

Further, most FL designs are not described in a way that enables readers or researchers to determine the extent to which classroom activities and assessments align with evidence-based guidelines (Låg and Sæle 2019). Identifying what theoretical frameworks are being used in FL and obtaining related evidence-based quality indicators for FL could help us outline, quantify and reduce this distorting variation.

\section{Aim and research questions}

As a consequence of the concerns outlined above, the aim in this article is to explore the links between FL and active learning. With the above observations regarding the lack of 
conceptualization around connections between FL and active learning, we ask the following research questions:

(1) What is the link between FL and active learning?

(2) To what extent is FL grounded in theory or theoretical frameworks, and how are these theories and frameworks described?

(3) Which subject specific fields are represented within the reviewed studies?

(4) Which methodologies are used in the reviewed studies?

By responding to these questions, we aim to demonstrate how and to what extent the empirical literature approaches FL as a pedagogical principle and not merely as a decontextualized technique.

\section{Theoretical framework}

The term 'active learning' and the related idea of 'student-centred learning' became a notable interest among teachers, educational researchers, cognitive psychologists and instructional designers during the late 1970s and early 1980s (Bonwell and Eison 1991). Active learning can take many forms, follow different models and serve many different instructional goals. Many of the approaches have areas of overlap with each other and draw on similar pedagogies that focus on student-centred instruction and course learning objectives. Despite the reported benefits of active learning, the challenge for instructors is how to find time to incorporate these strategies into their courses without sacrificing content coverage (Crouch and Mazur 2001). This dilemma, together with the rise of digitalization in education, contributed to the development of the 'inverted' or 'flipped' learning approach (Bishop and Verleger 2013; Lage, Platt, and Treglia 2000). FL stresses the idea of active engagement over lectures in the classroom, which is strongly interconnected with learning approaches that have been referred to as active learning, student-centred learning and problem-based learning (Prince 2004). These approaches are grounded in a constructivist philosophy - one of the more influential paradigms in contemporary educational theory since Piaget (e.g. 1957) - which holds that knowledge cannot be 'transmitted', but requires the active construction of meaning by the learner. Aligning with constructivist philosophy, FL approaches learning as a learner's active engagement with the content, the instructor and other students (Cheng, Ritzhaupt, and Antonenko 2019). While the assumption that learning requires active engagement is not new, nor especially revolutionary, our contemporary educational practices do not always reflect what we know about active learning.

However, from the empirical literature it is nearly impossible to understand what 'active learning' specifically entails, as the term is used to describe both methods and philosophies alike (Prince 2004). Though the term 'active learning' has never been precisely defined in educational literature, some general characteristics are commonly associated with the use of strategies promoting active learning in the classroom. One of the earliest definitions of active learning can be found in Bonwell and Eison's (1991) article, which has been cited over 7,500 times. The authors began their review of the literature on active learning by stating: 'Active learning is generally defined as any instructional method that engages students in the learning process. In short, active learning requires students to do 
meaningful learning activities and think about what they are doing' (Bonwell and Eison 1991, 2). Although we consider that to be a general description, we nevertheless find the definition appropriate and use it, ourselves, in this article. In 2004, Prince conducted another review of active learning, in its broadest sense. He concluded that there was extensive support for the effectiveness of active learning in the articles that he had analyzed; he also noted the difficulty in measuring its effectiveness due to the different definitions of and approaches to active learning across the literature. Prince (2004) describes active learning as activities that are introduced into a classroom, where the core elements are student activity and engagement in the learning process.

Relatedly, prior research suggests that students' knowledge, understanding and performance are improved via active learning (Freeman et al. 2014; Harris and Welch Bacon 2019; Lin and Hwang 2019). Despite these positive results, one obstacle with active learning is student resistance. Teachers implementing active learning techniques for the first time may face pushback from students unfamiliar with such an approach (Lambach, Kärger, and Goerres 2017). In addition, a recent study revealed that students prefer low-effort learning strategies - such as listening to lectures - despite performing better with active learning (Deslauriers et al. 2019).

Advocates of FL argue that the success of the model is due to its foundations in active learning pedagogy (Adams and Lenton 2017; Eichler and Peeples 2016; Jensen, Kummer, and Godoy 2015; Yang, Lin, and Hwang 2019). For instance, the difference in performance between flipped and traditional classrooms disappears when both use active-learning techniques (DeLozier and Rhodes 2017; O'Flaherty and Phillips 2015). Jensen, Kummer, and Godoy (2015) provide support for the hypothesis that the key to driving learning in the flipped setting is the inclusion of active learning. Moreover, research suggests that it is the presence of active learning, rather than the structure of the FL itself, that leads to higher student performance (Jensen, Kummer, and Godoy 2015). Some researchers even refer to FL as an instructional technique included in active learning pedagogy - see e.g. Harris and Welch Bacon (2019) and Yang, Lin, and Hwang (2019), or Alario-Hoyos et al.'s (2019) statement that ' $t \mathrm{t}$ ]he flipped classroom is a relatively new active learning strategy'.

This could add evidence in support of designing curricula that are grounded in active learning pedagogy. That is, discipline-based educational researchers should no longer focus on determining whether active learning strategies are more beneficial than traditional teaching methods, but should turn their attention toward investigating unresolved areas: for example, how active learning strategies facilitate learning in an FL intervention, or which student populations benefit most from which methods (Cheng, Ritzhaupt, and Antonenko 2019; Freeman et al. 2014; Leatherman and Cleveland 2019). However, as with any technique, active learning is not a panacea. Active learning techniques must be applied alongside consideration of the learning outcomes to make the learning process meaningful to the student (Drake 2012).

Taking into account the broader literature, however, there is a growing body of evidence supporting the argument that active learning is superior to the traditional lecture method (Bishop and Verleger 2013). The weight of this evidence led Freeman et al. (2014), who carried out a comprehensive meta-analysis comparing active learning to other lecture approaches, to conclude that it no longer makes sense to conduct studies using the traditional lecture method as a control (Freeman et al. 2014). They suggest that 
it would be more productive to focus on using advances in educational psychology and cognitive science to drive changes in education, and to test which types of active learning are most efficient and suitable - not unlike what Prince did in 2004.

Given this lack of precision around the concepts related to FL and the connection between FL and active learning, we recognized that a systematic review aimed at a clear synthesis of a fragmented body of literature was unrealistic. As such, we opted for a scoping review as our methodology.

\section{Methodology}

Scoping reviews are an increasingly popular methodology for seeking and mapping the evidence in broad topic areas, one that is also relevant for both emerging and established fields. With regard to the latter, in established fields where there may be an abundance of evidence, scoping reviews can provide an understanding of the 'lay of the land' (Colquhoun et al. 2014). The approach for this scoping review is based on the five-stage framework of Arksey and O'Malley (2005), proposed as a guide for ensuring methodological transparency and reliability of findings (O'Flaherty and Phillips 2015). The five-stage framework consists of (1) identifying the research question, (2) identifying relevant studies, (3) study selection, (4) charting the data and (5) collating, summarizing and reporting the results.

\section{Identifying the research question}

The research questions outlined in the introduction are aimed at exploring the link between FL and active learning and the characteristics of the research in this field: specifically, which theories or theoretical frameworks are described, and which subject fields and methodologies are represented.

\section{Identifying relevant studies}

Arksey and O’Malley (2005) suggest using broad search terms to obtain a comprehensive coverage of the relevant literature. Search terms were developed to capture literature that related to FL and active learning in higher education. The search string queried the databases for all results where the terms 'flipped' or 'inverted' occurred near terms like 'class', 'course' or 'learn' and in connection with different forms of active learning appearing in the title, abstract or keywords. 'Inverted' is often used interchangeably with the term 'flipped' and 'collaborative', while 'cooperative' and 'problem-based' are related to 'active learning'.

The literature searches were conducted in the Education Resources Information Centre (ERIC), Academic Search Premier, Web of Science and Scopus, which cover both field-specific and generic databases. The particular search string used in Scopus was TI (learn* N2 (active OR collaborative OR problem-based OR cooperative)) OR AB (learn* N2 (active OR collaborative OR problem-based OR cooperative)) OR KW (learn ${ }^{\star} \mathrm{N} 2$ (active OR collaborative OR problem-based OR cooperative)) AND TI ((flipped OR inverted) N2 (class ${ }^{\star}$ OR course ${ }^{\star}$ OR learn $\left.{ }^{\star}\right)$ ) OR AB ((flipped OR inverted) 
N2 (class ${ }^{\star}$ OR course ${ }^{\star}$ OR learn $\left.{ }^{\star}\right)$ ) OR KW ((flipped OR inverted) N2 (class ${ }^{\star}$ OR course ${ }^{\star}$ OR learn $\left.{ }^{\star}\right)$ ), and was limited to English and scholarly journals. No limits were set on publication date or study design. A similar search strategy was used in the other databases. The main search was conducted in February 2019, and this search was updated in December 2019.

\section{Study selection}

The search strategy yielded 1301 records in total. Duplicates were removed, and 752 unique records remained. The articles were screened by title and abstracts in the review tool EPPI-Reviewer 4, and conflicts were subsequently discussed and resolved. Articles that did not concern active learning in flipped classrooms in higher education were excluded. In total, 435 articles remained, and their full texts were retrieved for screening. Of these, 280 were excluded mainly due to an absence of theory or a theoretical framework; a few articles were excluded due to having an incorrect context (e.g. primary or secondary education), language or publication type (e.g. conference proceedings and other non-refereed publications). The inclusion and exclusion criteria are listed in Table 1. Finally, 155 articles were included for analysis (see Table 2). The PRISMA flow diagram in Figure 1 depicts the article selection process (Moher et al. 2009).

\section{Charting the data}

The qualitative data analysis software NVivo 12 Pro was used to extract data from the 155 articles. Specifically, NVivo was used to map the overall findings of the articles, in addition to the methodological descriptions. The relationship between FL and active learning was examined by using the text search function in NVivo across the material. The following data were extracted from the included articles in a Microsoft Excel spreadsheet: authors, year of publication, the subject field of the population, methodology and pedagogical theory/theoretical framework (Table 2).

\section{Collating, summarizing and reporting the results}

The results were mainly summarized and reported by percentages and numbers (see Figure 2 for academic subject/field). The use of pedagogical theories or theoretical frameworks were categorized and captured in a figure to illustrate the relationships between the theories (Figure 3). The overall findings of the studies were then summarized.

Table 1. Inclusion and exclusion criteria.

\begin{tabular}{ll}
\hline Inclusion criteria & Exclusion criteria \\
\hline Active learning in flipped classroom & Other teaching methods \\
Higher education & Other educational levels \\
Pedagogical framework or theory & Missing pedagogical theories \\
English language & Other languages \\
Peer-reviewed original research & Non-refereed publications \\
\hline
\end{tabular}




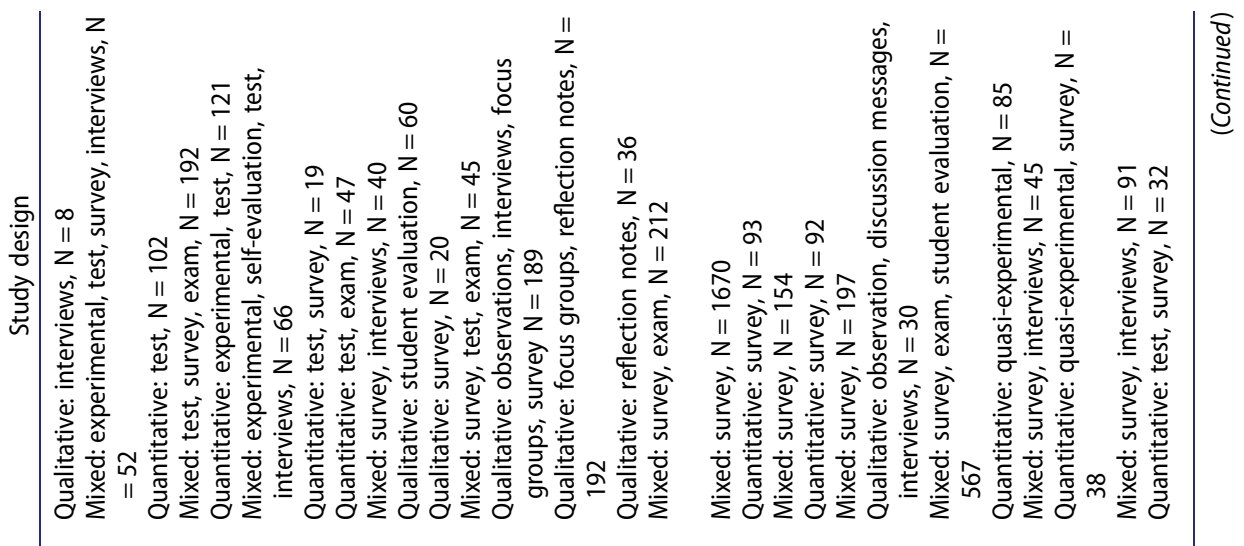
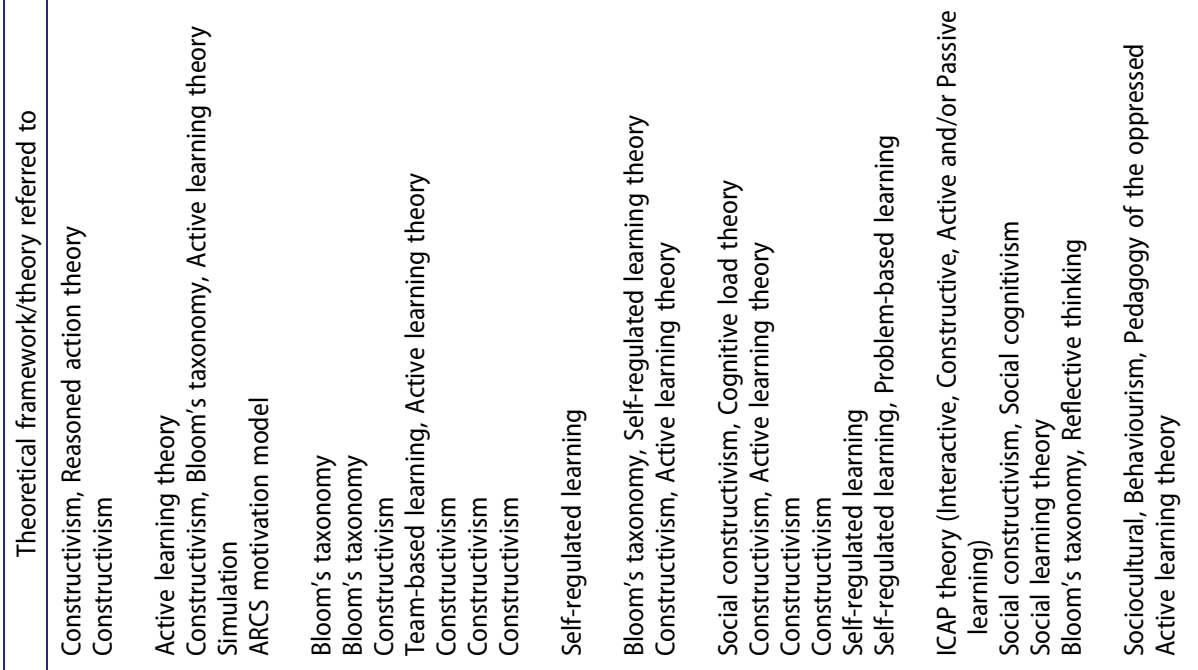

$\underset{\frac{\sigma}{\omega}}{c}$

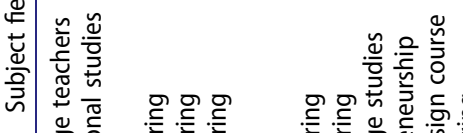

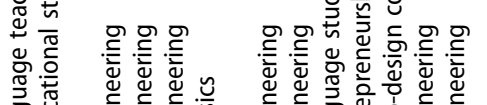

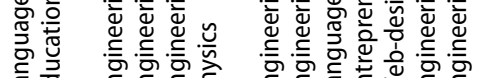

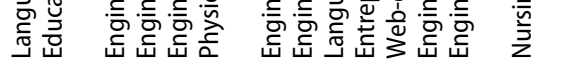

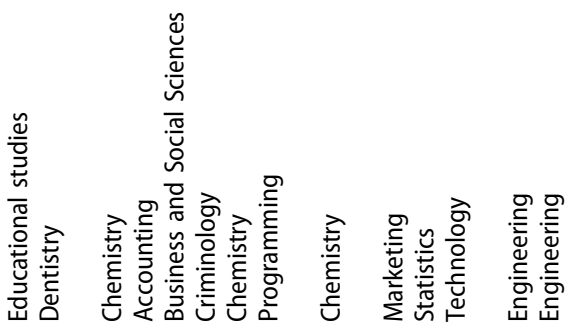

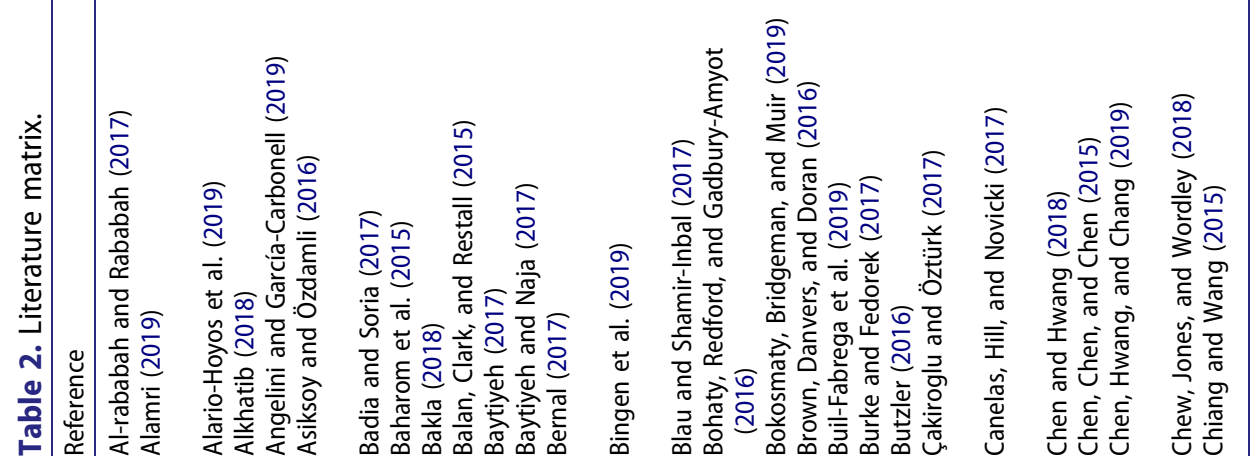


In:m

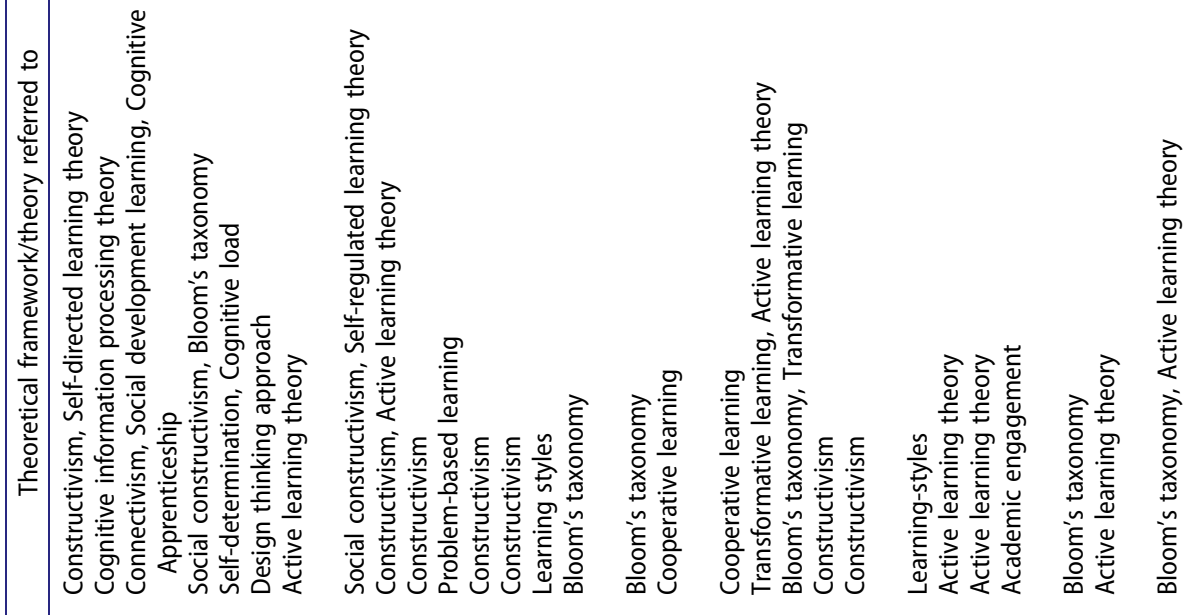

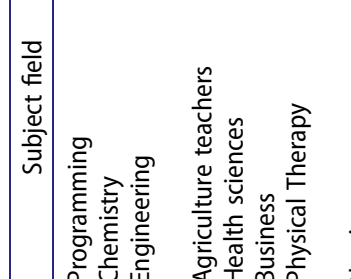

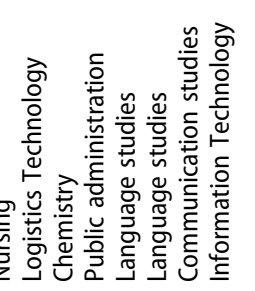

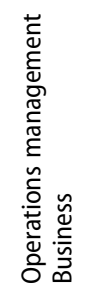

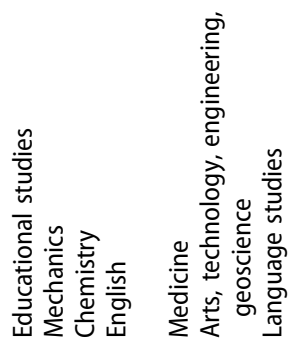

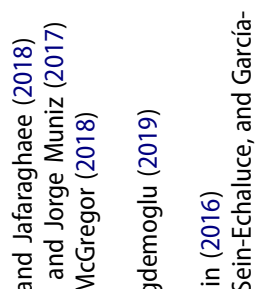

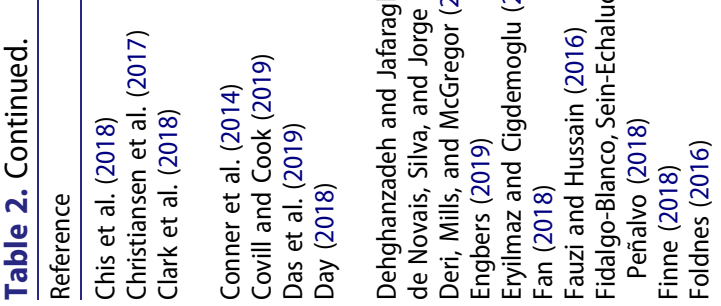

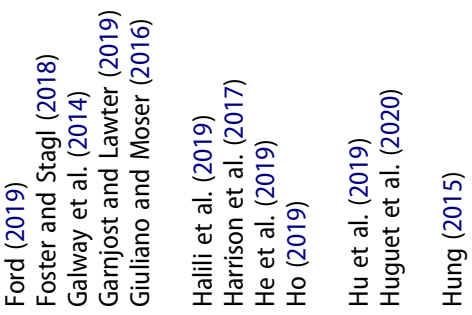




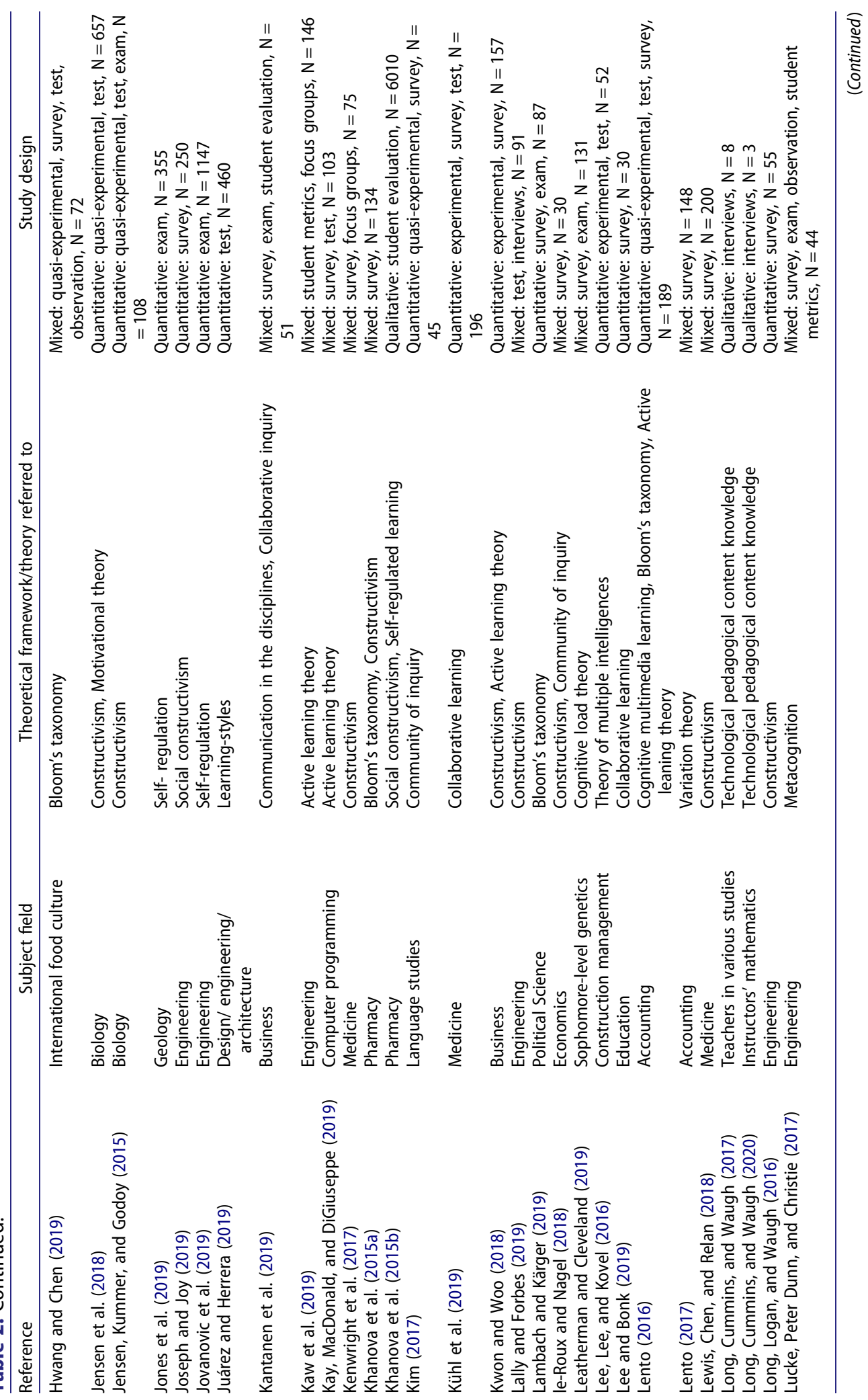




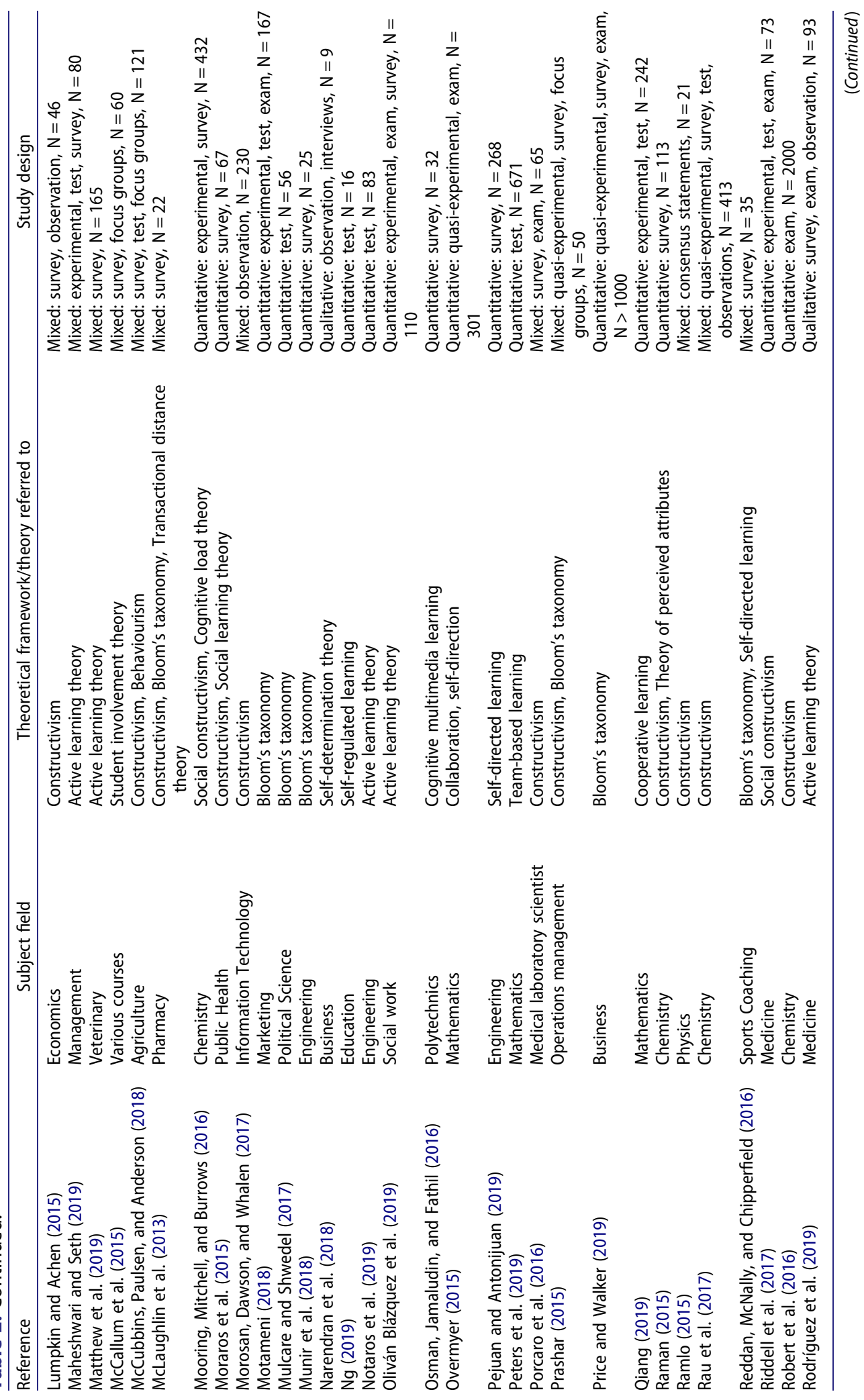




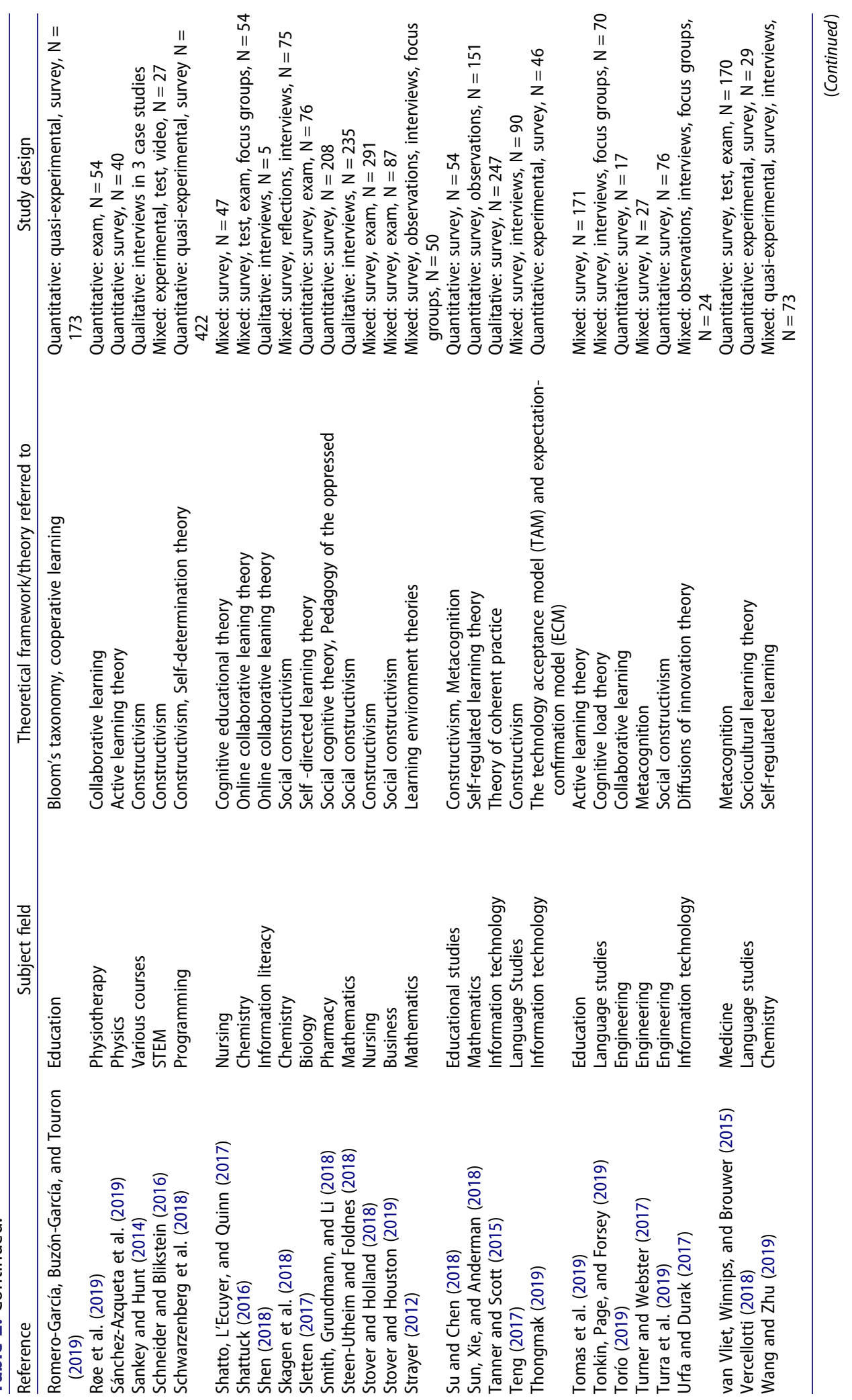




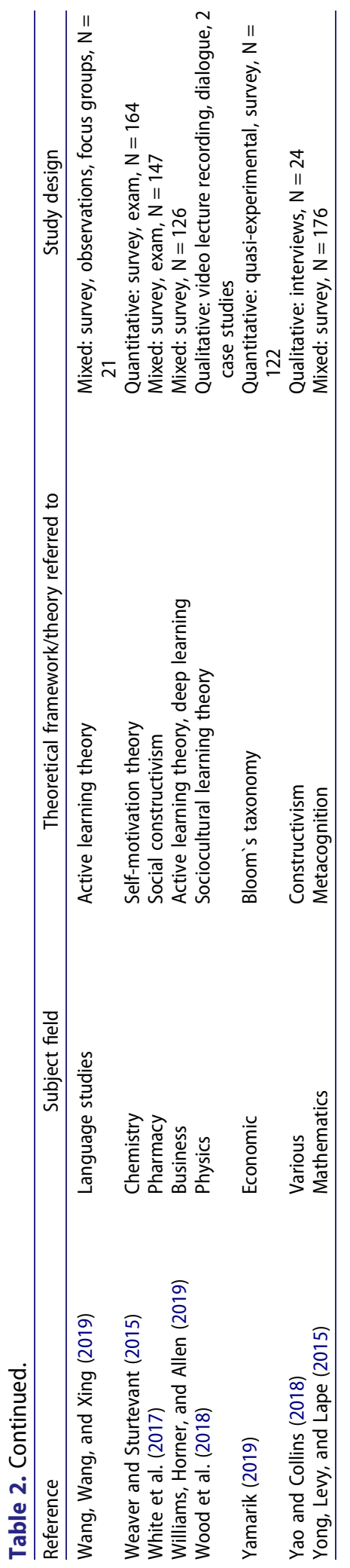




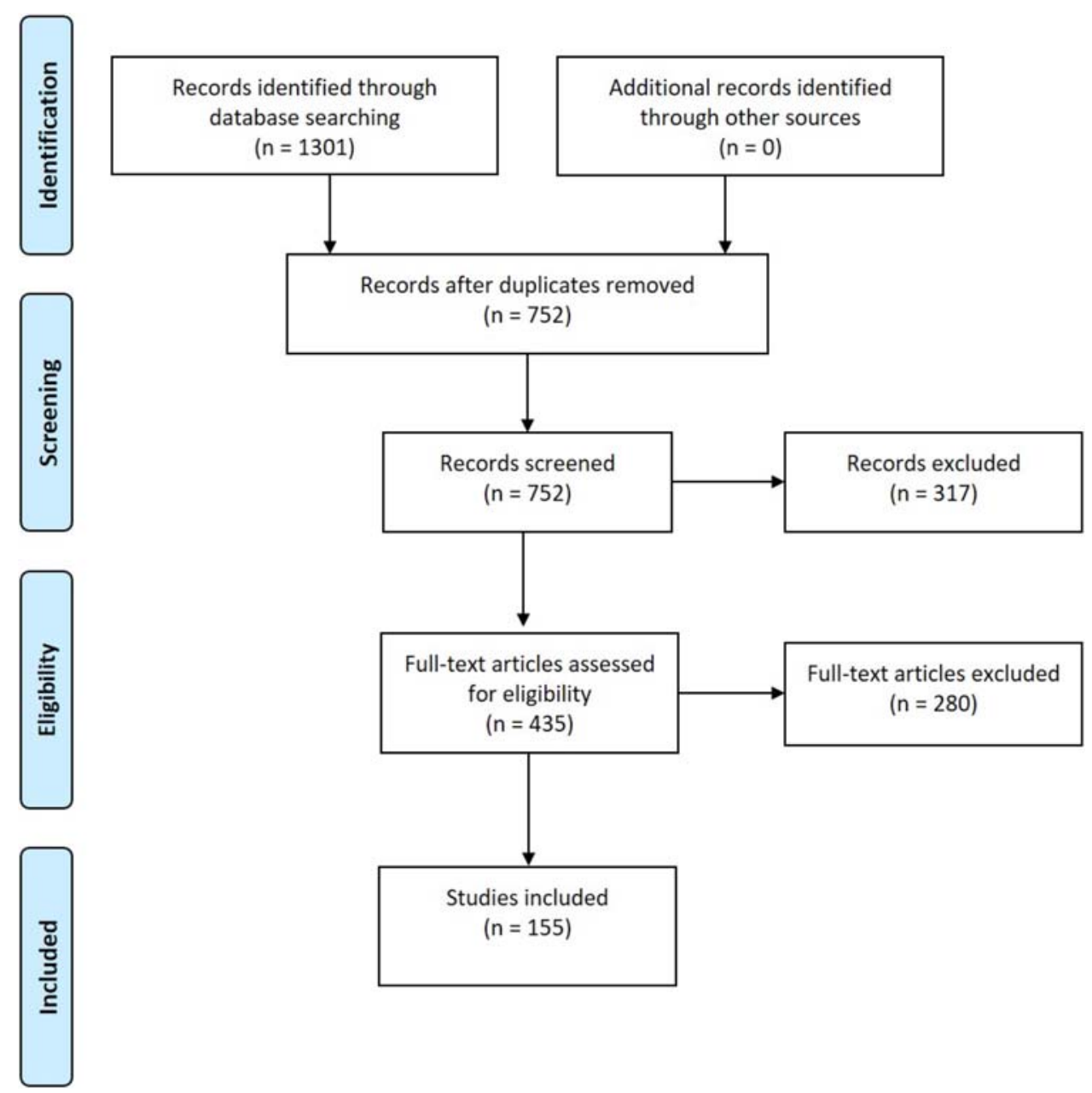

Figure 1. PRISMA flow diagram.

\section{Results}

Approximately $65 \%$ of the 435 articles retrieved in full text did not connect their research to theory or a theoretical framework. In the remaining $35 \%$ of the 435 articles, there were some cases for which it was difficult to determine which theoretical framework or methodology was used. Across the articles, the description of these elements varied from one sentence - e.g. 'the flipped classroom has underpinnings in both the constructivist and social learning theory' (Moraros et al. 2015, 15) - to entire sections (e.g. Blau and Shamir-Inbal 2017). The most frequently theoretical framework referred to was constructivism; $68 \%$ of the 155 included articles referred to constructivism and related perspectives invoking active learning as a theoretical concept. Active learning and similarly specific terms were explicitly mentioned in $23 \%$ of the articles. We classified $25 \%$ of the articles under 'instructional design models' or 'other', while Bloom's taxonomy was mentioned in $14 \%$ of the articles (Figure 3 ). The included articles were primarily published in 


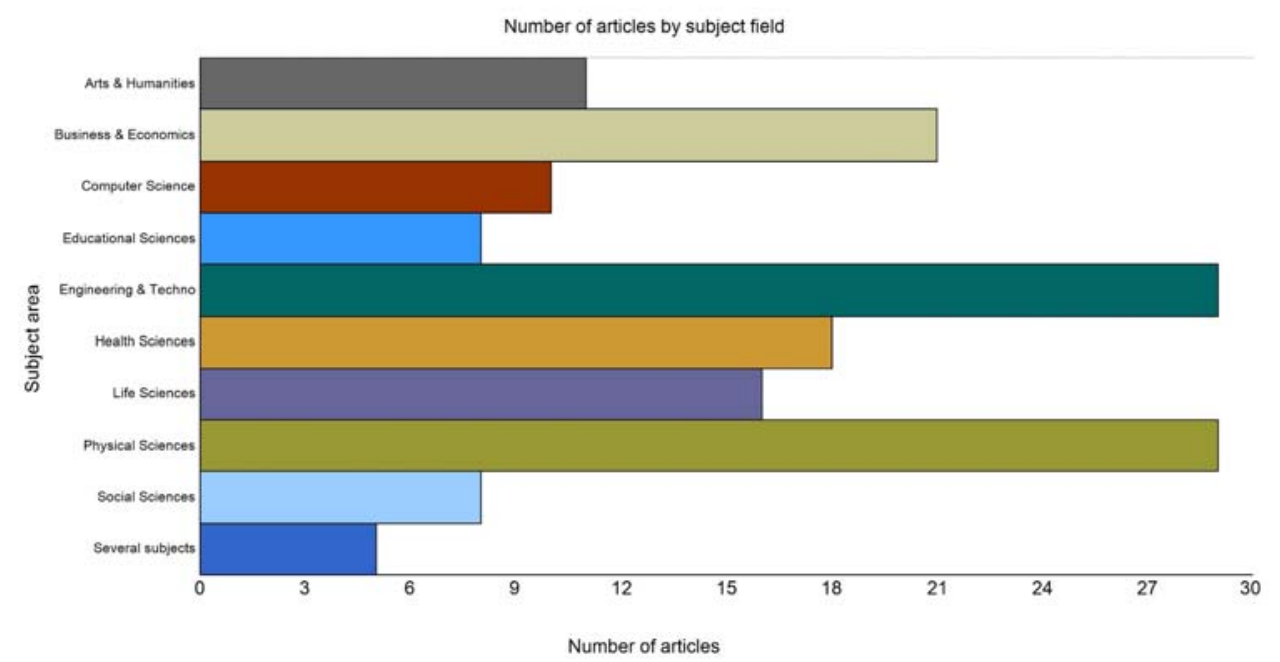

Figure 2. The subject area of the flipped classroom interventions.

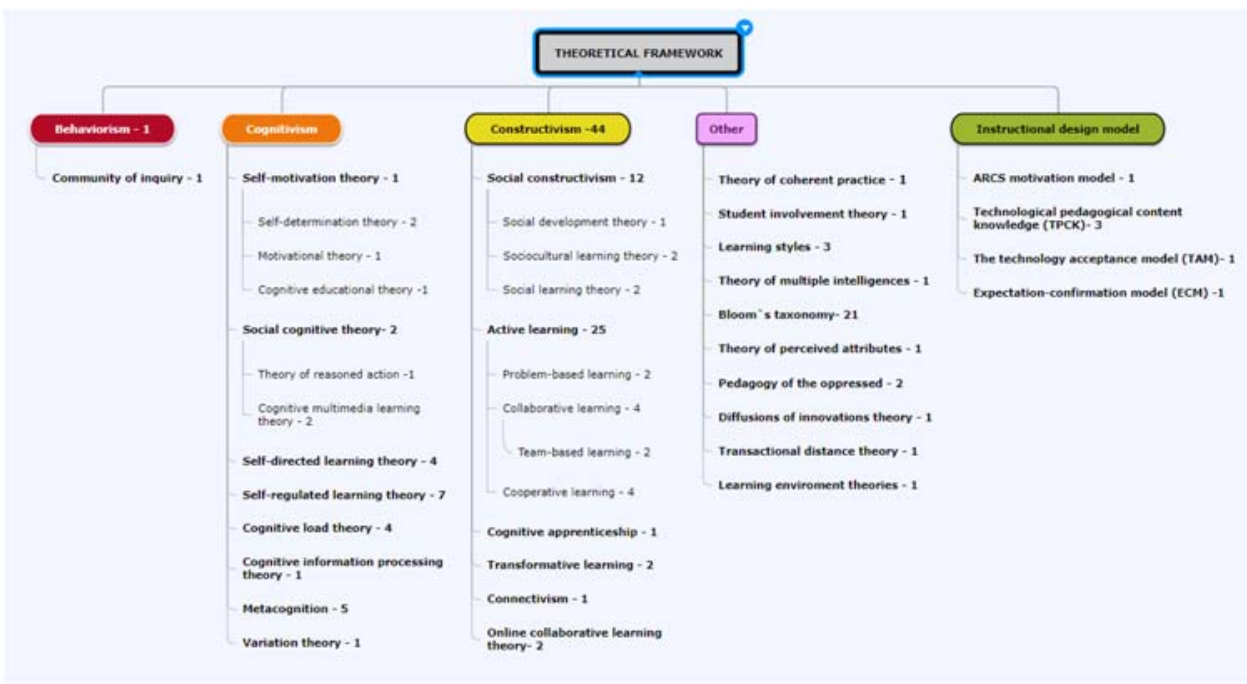

Figure 3. Theoretical frameworks reported in the included studies.

subject-specific journals (e.g. engineering, chemical or pharmaceutical journals) but also in some journals focused on pedagogy and research in higher education.

FL has been used as an approach to teaching in a wide variety of academic subject areas. Figure 2 shows this variety based on an analysis of the included articles in this study. The most common subject area for FL is the STEM subjects: engineering, technology, and the physical sciences (e.g. physics, chemistry and mathematics). These are followed by subjects relating to business and economics, and in the health sciences and life sciences (biology, pharmacy and agriculture). Common across these subjects is their preference for numbers, formulas, models and hard facts, while 'softer' subjects - such as 
those in the social sciences and the arts and humanities - are less represented in the reviewed articles.

A quantitative study design was the most common methodology used, accounting for $46 \%$ of the included studies. Qualitative studies accounted for 14\%, and mixed (qualitative and quantitative) methods were used in $40 \%$ of the included articles. About 25\% of the studies used either a quasi-experimental (e.g. Rau et al. 2017; Schwarzenberg et al. 2018) or an experimental study design (e.g. Foldnes 2016; He et al. 2019) with pre-tests and/or post-tests to measure the effect of FL compared to traditional teaching. Test scores and grades were compared across the intervention group and the control group. Surveys collecting quantitative and, in many cases, qualitative data were another frequently used methodological instrument (e.g. Bokosmaty, Bridgeman, and Muir 2019; Lewis, Chen, and Relan 2018). The quantitative questions typically measured learning outcomes, and the qualitative open-ended questions captured students' attitudes and preferences regarding the FL intervention. The qualitative studies were mainly based on various types of interviews (e.g. Bingen et al. 2019; Steen-Utheim and Foldnes 2018).

Most of the studies that quantified the effectiveness of FL reported higher grades and diminished failure rates in the FL group (e.g. Mooring, Mitchell, and Burrows 2016; Røe et al. 2019). Test scores were significantly higher with regard to critical thinking (e.g. McCubbins, Paulsen, and Anderson 2018; van Vliet, Winnips, and Brouwer 2015), teamwork (e.g. Huguet et al. 2020; Morosan, Dawson, and Whalen 2017) and learning motivation (e.g. Lucke, Peter Dunn, and Christie 2017; Su and Chen 2018). A few studies were inconclusive with regard to learning outcomes (e.g. Covill and Cook 2019; Garnjost and Lawter 2019).

The qualitative data mainly demonstrated higher satisfaction with FL (Hung 2015; Teng 2017), increased engagement (e.g. Fauzi and Hussain 2016; Steen-Utheim and Foldnes 2018), enhanced learner empowerment (e.g. Fauzi and Hussain 2016; McLaughlin et al. 2013) and increased interaction between students and/or students and faculty (e.g. Al-rababah and Rababah 2017; Matthew et al. 2019).

However, some studies point to the challenges of adapting to an active learning style, especially as it is more time consuming and demanding (e.g. Bingen et al. 2019; Røe et al. 2019). In addition, studies suggest that students need to learn strategies for active learning (Balan, Clark, and Restall 2015; Butzler 2016), including how to prepare at home (Burke and Fedorek 2017; Harrison et al. 2017).

As can be seen in Figure 3, FL is related to several different theories, conceptual frameworks and approaches in the reviewed articles. The categorization scheme depicted in Figure 3 was inductively constructed from the selection process described above and in Figure 1, but also with a view to a series of well-established theoretical perspectives. However, these perspectives rarely come across as clear-cut or fully applied. For example, some of them mention constructivism very briefly, while others mention connectivism and relate it to constructivism but without further explanation. In addition, none of the selected articles refer to cognitivism specifically, but to perspectives originating from cognitivism - such as self-regulated learning (SRL). Some studies have entire sections devoted to learning theory, while others offer only two sentences. Under the category 'other', we have subsumed approaches used in the articles that do not adhere to more well-established theoretical perspectives; one example is Bloom's taxonomy, 
which emerged as one of the three most frequently used approaches in the articles. In addition, among the most widely used approaches under constructivism, we find the notion of 'active learning', with its subcategories of problem-based, collaborative and cooperative learning - in accordance with Prince's (2004) definition. Finally, we grouped any approaches that could be classified under the instructional design model (Carr-Chellman and Reigeluth 2009).

The above results reflect a complex and diverse landscape with regard both to how FL has been perceived and how it has been studied. In the following, we seek to relate this complexity to the research questions in order to distil principles underlying FL and how it connects to active learning.

\section{Discussion}

\section{Active learning}

Our first research question queried the link between FL and active learning. The selected studies indicate that this link is rarely explicitly addressed or operationalized. Active learning, with its three subcategories of problem-based, collaborative and cooperative learning, is mentioned in $23 \%$ of the articles in our review. Few studies explicitly define their definition of active learning. Most describe active learning in very general terms, sometimes only 'namedropping' it (see, for example, McLaughlin et al.'s [2013] and Day's [2018] frequently cited articles). The notion of active learning seems to be taken for granted as being positive for learning; moreover, many studies convey more of an intuitive understanding of active learning than a shared definition, as exemplified by the following excerpt: 'An effective way to achieve excellent learning results is individual one-on-one tutoring (Bloom [1956] 1984), which is characterised by rich instructor-student interaction and active learning' (Finne 2018, 6). The term 'active learning' occurs 13 times in this article, but is never clearly defined.

However, there are some exceptions. Some articles refer to empirical literature on active learning, e.g. Alkhatib (2018), Harrison et al. (2017), Lumpkin and Achen (2015) and Foster and Stagl (2018). The latter article contains a theoretical section concerning a pedagogical model based on three contemporary theories of learning: (1) student-centred learning, (2) active learning and (3) transformative learning. Further, the authors argue that these theories have roots in constructivism or social constructivism, with a view toward the 'zone of proximal development' (Vygotskij 1978). They present a conceptual framework for the design, implementation and evaluation of FL, entitled the 'inverted classroom model'. Moreover, they define active learning following the broad, but widely accepted, definitions of Prince (2004) and Bonwell and Eison (1991) - we found that other articles also base their definition of active learning on the same. For example, Hung $(2015,82)$ states the following: 'Conceptually, active learning is an umbrella term that involves students in doing things and thinking about the things they are doing'. This definition links active learning to an assortment of learning methods and activities, instructional strategies and any approach with the goal of activating the students in the learning process. Examples of these approaches found in the review articles include collaborative learning, cooperative learning, problem-based learning and team-based learning. 


\section{Theoretical framework}

Our second research question queried the extent to which FL is grounded in theory or theoretical frameworks. All research articles should have a valid theoretical framework to justify the importance and significance of the work (Lederman and Lederman 2015). Approximately 65\% of the 435 full-text articles retrieved do not connect their research to theory or a theoretical framework. Of the remaining 35\%, the theoretical and conceptual underpinnings are vaguely described, with a few exceptions. Thus, it was challenging to identify the inner logic amidst the theoretical diversity of the studies reviewed.

In the following sections, we have classified studies such that their conceptual underpinnings correspond to well-established theoretical categories. This should not be seen as an exercise of 'forced matchmaking' but rather as an overview of where studies of FL turn to increase their explanatory power. As a result, not all categories would qualify as theoretical frameworks, per se - e.g. Bloom's taxonomy (see below) - but have been subsumed under this term, as they inductively emerge when examining the studies' conceptual references.

\section{Constructivism}

In total, $68 \%$ of the 155 included articles refer to constructivism and other perspectives originating from constructivism. Constructivism emphasizes active learning by placing students at the centre of the learning process, replacing passive listening with active participation (King 1993). As its name suggests, constructivism understands knowledge to be constructed rather than 'given' or discovered. As a result, learning becomes a matter of restructuring pre-existing modes of thinking rather than accumulating information. Teaching involves the facilitation of this thinking, not the imparting of facts. Further, constructivism posits that making use of communication and interactive activities in which learners play engaged and active roles can motivate learning more effectively than activities in which learners are inactive (Olusegun 2015).

Such constructivist fundamentals can be traced in excerpts such as this one:

The basis of flipped learning is active learning and builds on constructivism (...). It embraces problem-based learning, peer-assisted learning, cooperative learning, and collaborative learning under active learning (...). After all, flipped learning, which stresses the instructor's role as a coach, is a pedagogical option to provide opportunities for interactive and dynamic engagement in the learning process. (Kwon and Woo 2018, 3)

Many articles only briefly describe or do not explicitly explain or define constructivism using references to the literature, as we see in this article: 'The flipped model employs a constructivist approach to learning. In this approach, students learn by experiencing and are responsible for building their knowledge' (Giuliano and Moser 2016). Even in a highly cited article by Jensen, Kummer, and Godoy $(2015,1)$, there is a lack of a clear definitions; the authors state only, 'We conclude that the flipped classroom does not result in higher learning gains or better attitudes compared with the nonflipped classroom when both utilize an active-learning, constructivist approach'. 


\section{Social constructivism}

In our review, we found $11 \%$ of the 155 included articles refer to social constructivism and other perspectives originating from social constructivism as a theoretical framework (e.g. social development theory). Within the constructivist family, there are several differing positions, of which social constructivist is one. Social constructivism does not take individual cognition as its point of departure but rather posits that knowledge is constructed socially by engaging in interactions.

One example of how this perspective is reflected in the articles we reviewed can be found in Khanova et al. (2015b, 1039), who write:

This pedagogical approach is underpinned by a combination of self-regulated and socioconstructivist learning theories. The former views students as active constructive participants in the learning process, whereas the latter emphasises the role of learning interactions, such as classroom discussions, in developing higher-order cognitive skills like reasoning and problem solving.

Another example is Dehghanzadeh and Jafaraghaee's $(2018,152)$ assertion that

FC is based on the self-regulated and socio-constructivist theories of learning. The self-regulated learning theory considers the learner as an active participant in the process of learning while the socio-constructivist theory puts greatly values the role of classroom discussions and interactions in promoting higher-order cognitive skills.

\section{Cognitivism}

In our study, $21 \%$ of the 155 included articles refer to theories that originated from cognitivism, such as cognitive load theory and self-determination theory, SRL: these share fundamental assumptions about knowledge as a result of processes of acquisition and developing mental structures, often connected to problem solving. None of the articles refer explicitly to cognitivism or similar terms. For example, SRL - a conceptual framework that includes the cognitive, metacognitive, behavioural, motivational and emotional/affective aspects of learning - is referred to in 5\% of the reviewed studies. However, in the articles we reviewed, SRL can be seen as an umbrella term capturing numerous cognitive variables influencing learning (e.g. self-efficacy, volition and cognitive strategies) (Panadero 2017). In these articles, SRL, students' motivation, and learning are treated as interdependent processes that cannot be understood apart from each other. For example, in Blau and Shamir-Inbal (2017, 72), we find the following: 'Selfregulated learning (SRL) refers to one's ability to monitor his or her learning and think meta-cognitively, motivationally, and behaviourally'. This same study claims that all SRL is determined by external rewards or punishment - not unlike mechanisms we know from behaviourism. FL poses higher demands on the self-regulation of students than in traditional models of content delivery. In practice, for students this means well-defined SLR outside the classroom, often assisted by technology (Blau and Shamir-Inbal 2017). Notably, it is critical for teachers to use proper methods to keep students on the right track prior to class, with regard to learning: this can be done e.g. through pre-class assignments and online quizzes (Cheng, Ritzhaupt, and Antonenko 2019). In this context, then, SRL becomes especially relevant with its 
emphasis on students' control of their learning environments as part of their cognitive efforts to reach educational goals.

\section{Bloom's taxonomy}

In our study, 14\% of the 155 included articles refer to Bloom ([1956] 1984) taxonomy. This taxonomy is a hierarchical classification of the different levels of knowledge in the learning process and, as noted in the introduction to this section, does not strictly qualify as a conceptual framework or 'theory' (although it often resonates with cognitive assumptions). After being revised in 2001, the taxonomy proposes the following levels in the cognitive domain: (1) remembering, (2) understanding, (3) applying, (4) analysing, and (5) evaluating information and knowledge (Krathwohl 2002). The taxonomy is hierarchical, because each level is based on the previous one and can be reinforced and developed through social interaction and students' active learning. To be able to apply knowledge (Level 3), a student must have both the necessary knowledge (Level 1) and understanding (Level 2). Blau and Shamir-Inbal $(2017,79)$ provide an example of how Bloom's taxonomy is used as a framework in the studies we reviewed: 'This study suggests a re-designed model of flipped learning and discusses the added value of technologies in promoting higher order thinking skills presented in Bloom's taxonomy, such as applying, analysing, evaluating, and creating during both in- and out-of-class learning'.

It would seem that a number of the studies in our analysis found Blooms' taxonomy relevant to FL, in that the transmission of knowledge is obtained independently and outside of class, while the assimilation of knowledge - which requires greater critical reasoning - occurs during class under the guidance of teachers or peers. The higher the level, the more assimilation is required; the lower the level, the more transmission of information occurs through largely independent assimilation (Lambach, Kärger, and Goerres 2017; McLaughlin et al. 2013; Moraros et al. 2015; Reddan, McNally, and Chipperfield 2016).

Some educators claim that the use of FL in education corresponds directly to the objective embedded in Bloom's taxonomy; that is, to help students develop higherorder thinking skills by way of flipped instruction, which is assumed beneficial for both lower- and higher-order skills development (Ahmed 2016).

\section{Flipped learning in subject-specific fields}

In our review, FL approaches are described across a wide range of disciplines in which STEM subjects most commonly employ FL (see Figure 3). Similar findings are described in Lundin et al.'s (2018) systematic review. This contrasts with a new meta-analysis of FL, however, which found that most of the FL studies are connected to health professions (Låg and Sæle 2019).

The 'lecture-based' and 'teacher-centred' approaches are a 'signature pedagogy' of many STEM disciplines and fields (Freeman et al. 2014; Winberg et al. 2019). Mason, Shuman, and Cook (2013) claim that although there is a pressing need to reorganize engineering education, for example, the traditional lecture style of teaching remains the norm in college courses around the world. Students are familiar with this method 
and are generally comfortable in the traditional classroom. On the other hand, because FL emphasizes active participation during class, it is argued that STEM-based subject areas, which often involve the application of concepts, labs and problem sets, may be well-suited to this method. Freeman et al. (2014) conducted a comprehensive metaanalysis (225 studies) of STEM courses, comparing traditional lecturing versus active learning, and found that the average examination score improved in active learning sessions.

In addition to STEM-based subjects, many of the reviewed articles originated from the health sciences. Similar findings are described in a meta-analysis of FL (Låg and Sæle 2019). The same article claims that most meta-analyses of flipped classroom studies are limited to the medical and health professions disciplines. The flipped learning approach has grown rapidly and is now widely used in health professions education (Hew and Lo 2018). The results of a systematic review (Betihavas et al. 2016) indicate the potential for flipped learning to transform nursing education, provide a studentcentred approach and offer increased opportunities for students to develop critical thinking skills.

\section{Methodological aspects in the studies}

In the reviewed studies, we also found a wide variety of research designs and methodological approaches. Quantitative study design accounted for $46 \%$ of the included studies, qualitative studies for $14 \%$ and mixed-methods for $40 \%$. This is consistent with findings from Steen-Utheim and Foldnes (2018), who found that mixed methods are one of the most widely used methods for studying FL after quantitative methods; the authors also conclude that there is a lack of in-depth qualitative research on students' perceptions of FL.

Several authors have noted the lack of a rigorous evaluation of FL (Låg and Sæle 2019). However, to objectively measure the effect of FL, a controlled experimental study design with pre-test and post-test is considered the gold standard (Bishop and Verleger 2013). About 25\% of our 155 studies has an experimental or quasi-experimental design. Yet, some of the studies are based on a post-test only and several are small scale studies with $\mathrm{N}<100$. Foldnes (2016) may be considered as one of the more robust studies, which is an experimental study running throughout one semester and with pre-test, post-test and exam scores. Student performance was measured across ten classes in six campuses in the largest cities in Norway $(\mathrm{N}=1569)$. Test and exam scores highly increased with collaborative and active learning elements. Although there may be scant evidence as to the FL approach being more 'effective' or producing better results than lecture-based teaching, there are strong indications that active learning leads to better student performance (Låg and Sæle 2019). As the FL approach prioritizes the active student, one can argue that FL interventions are conducive to improved student performance.

Five years after O'Flaherty and Phillips (2015) claimed that FL is under-theorized, we still find a lack of consistent and articulated theoretical perspectives and a multitude of analytical approaches. We found few articles that explicitly invoked a theory in terms of explanatory power or specific references to a body of conceptually oriented literature. Most of the studies refer to a mix of pedagogical terms or approaches (e.g. transformative 
learning, self-determination theory and online collaborative learning) without describing or theoretically differentiating them fully. For example, a very influential experience is reported in Bergman and Sams' account of the use of FL in their chemistry class; although they demonstrated a positive effect, the data was mostly anecdotal (Tucker 2012). This eclecticism and reluctance to connect FL with a specific paradigm correspond with findings from other reviews on FL (Cheng, Ritzhaupt, and Antonenko 2019; Lundin et al. 2018). The lack of applied theoretical frameworks in the FL literature can also be understood within the context of FL's emergence from classroom practice as a cluster of techniques that worked well, rather than a conceptualization resulting from scientific educational research (Seery 2015).

To summarize, our analysis has shown that interest in FL has grown in recent years, perhaps due to an increased interest in active learning and the ways FL can support and sustain this pedagogical principle when operationalized. However, as the phenomenon of FL has continued to make an impact across several disciplines, it has become important to identify its conceptual underpinnings and the basis on which its claims for success are made. As with the connections between FL and a diversity of conceptual frameworks, methodologies also reflect a 'multi-paradigmatic' approach depending on whether studies aimed to e.g. measure effects or examining students' perceptions. Our scoping review also indicates that diversity is utilized in order to better capture an emergent and not yet 'stable' phenomenon. However, it might also reflect researchers' sheer uncertainty as to how best to examine the phenomenon. Regardless, our scoping review reflects a situation where a plethora of conceptual and analytical approaches exist and where such approaches are only rarely argued or elaborated. Thus, FL might run the risk of being reduced to a 'technique' or a 'universal tool', instead of potentially becoming a generative concept for educational development.

\section{Limitations}

An initial literature search proved that there is a considerable amount of research on FL. We limited our search to FL related to specific forms of active learning in order to examine to what extent and how this relationship FL was conceptualized. The searches were further restricted to four of the largest and most important databases: our aim here was not to be exhaustive, but rather to obtain a broad overview of the research field. Our main interests were the theoretical and methodological framework(s) used; however, it proved challenging to identify the use of these frameworks in several of the articles. We also discussed where to draw the line for inclusion and exclusion with regard to theoretical description(s): we opted to include even very short descriptions. Despite these limitations, we are confident that the number of articles included provide a representative view of the theoretical and methodological challenges of this research field.

\section{Conclusion}

One conclusion that can be drawn from the present study is that, although the number of FL articles has seen rapid growth since 2011, we still find a lack of principally applied theoretical perspectives and/or conceptual frameworks. Approximately 65\% of the 435 
full-text articles retrieved do not make such connections explicit. For the remaining 35\%, the theoretical and conceptual underpinnings are generally only vaguely described in the screened corpus, although with a few exceptions. In sum, the reviewed literature reflects a 'multi-paradigmatic' approach. We propose that the popularity of FL could be explained by and accounted for by such a pragmatic but unprincipled approach. Our scoping review seems to indicate that, in the surveyed literature on FL, theoretical and methodological eclecticism and diversity are favoured as better capturing an emergent and not yet 'stable' phenomenon.

As previously emphasized, research is important for robust knowledge development, and convincing research applies - or is influenced by - a scientifically grounded paradigm. As we have found eclecticism and a reluctance to connect FL with elaborated theoretical perspectives or established paradigms, we propose that further development of FL as an instructional methodology would benefit from the use of more principled views on learning and instruction. In this case, it would involve robustly establishing the connections between a pedagogical principle (active learning) and a didactic principle (flipped learning).

\section{Disclosure statement}

No potential conflict of interest was reported by the author(s).

\section{ORCID}

Andreas Lund (1) http://orcid.org/0000-0003-0175-400X

Anita Nordsteien (D) http://orcid.org/0000-0002-8397-0795

\section{References}

Abeysekera, Lakmal, and Phillip Dawson. 2015. "Motivation and Cognitive Load in the Flipped Classroom: Definition, Rationale and A Call for Research." Higher Education Research \& Development 34 (1): 1-14. doi:10.1080/07294360.2014.934336.

Adams, Rhys, and Kevin Lenton. 2017. "Engaging Colleagues in Active Learning Pedagogies Through Mentoring and Co-Design." Proceedings of the 14th Conference on Education and Training in Optics and Photonics. doi:10.1117/12.2266663.

Ahmed, Hanaa Ouda Khadri. 2016. "Flipped Learning as a New Educational Paradigm: An Analytical Critical Study.” European Scientific Journal 12 (10): 417-444. doi:10.19044/esj. 2016.v12n10p417.

Al-rababah, Ibraheem Hasan, and Luqman Rababah. 2017. "Investigating Arabic to Speakers of Other Languages (ASOL) Lecturers' Attitudes towards Utilizing Flipped Classroom Instruction (FCI): A Qualitative Study at Jordanian Public Universities." International Education Studies 10 (7): 94-102. doi:10.5539/ies.v10n7p94.

Alamri, Mahdi M. 2019. "Students' Academic Achievement Performance and Satisfaction in a Flipped Classroom in Saudi Arabia." International Journal of Technology Enhanced Learning 11 (1): 103-119. doi:10.1504/IJTEL.2019.096786.

Alario-Hoyos, Carlos, Iria Estevez-Ayres, Carlos Delgado Kloos, Pedro J. Muñoz-Merino, Enrique Llorente-Perez, and Julio Villena-Roman. 2019. "Redesigning a Freshman Engineering Course to Promote Active Learning by Flipping the Classroom through the Reuse of MOOCs." International Journal of Engineering Education 35 (1): 385-396. 
Alkhatib, Omar J. 2018. “An Interactive and Blended Learning Model for Engineering Education.” Journal of Computers in Education 5 (1): 19-48. doi:10.1007/s40692-018-0097-x.

Angelini, Maria Laura, and Amparo García-Carbonell. 2019. "Enhancing Students' Written Production in English through Flipped Lessons and Simulations." International Journal of Educational Technology in Higher Education 16 (1), doi:10.1186/s41239-019-0131-8.

Arksey, Hilary, and Lisa O’Malley. 2005. “Scoping Studies: Towards a Methodological Framework.” International Journal of Social Research Methodology 8 (1): 19-32. doi:10.1080/ 1364557032000119616.

Asiksoy, Gülsüm, and Fezile Özdamli. 2016. "Flipped Classroom Adapted to the ARCS Model of Motivation and Applied to a Physics Course." Eurasia Journal of Mathematics, Science and Technology Education 12 (6): 1589-1603. doi:10.12973/eurasia.2016.1251a.

Badia, José D., and Vicente Martínez Soria. 2017. "Creative Project-Based Learning to Boost Technology Innovation.” Attic-Revista D Innovacio Educativa 18: 1-13. doi:10.7203/attic.18. 9019.

Baharom, Shahrizan Bin, Muhamad Azry Khoiry, Roszilah Hamid, Azrul A. Mutalib, and Noraini Hamzah. 2015. "Assessment of Psychomotor Domain in a Problem-Based Concrete Labrotary." Journal of Engineering Science and Technology 10: 1-10.

Bakla, Arif. 2018. "Learner-Generated Materials in a Flipped Pronunciation Class: A Sequential Explanatory Mixed-Methods Study." Computers and Education 125: 14-38. doi:10.1016/j. compedu.2018.05.017.

Balan, Peter, Michele Clark, and Gregory Restall. 2015. "Preparing Students for Flipped or TeamBased Learning Methods.” Education + Training 57 (6): 639-657. doi:10.1108/ET-07-2014-0088.

Baytiyeh, Hoda. 2017. "The Flipped Classroom Model: When Technology Enhances Professional Skills.” International Journal of Information and Learning Technology 34 (1): 51-62. doi:10. 1108/ijilt-07-2016-0025.

Baytiyeh, Hoda, and Mohamad K. Naja. 2017. "Students' Perceptions of the Flipped Classroom Model in an Engineering Course: A Case Study." European Journal of Engineering Education 42 (6): 1048-1061. doi: 10.1080/03043797.2016.1252905.

Bernal, Carolina M. Rodriguez. 2017. "Student-Centred Strategies to Integrate Theoretical Knowledge into Project Development within Architectural Technology Lecture-Based Modules." Architectural Engineering and Design Management 13 (3): 223-242. doi:10.1080/ 17452007.2016.1230535.

Betihavas, Vasiliki, Heather Bridgman, Rachel Kornhaber, and Merylin Cross. 2016. "The Evidence for 'Flipping Out': A Systematic Review of the Flipped Classroom in Nursing Education." Nurse Education Today 38: 15-21. doi:10.1016/j.nedt.2015.12.010.

Bingen, Hanne Maria, Simen A. Steindal, Rune Krumsvik, and Bodil Tveit. 2019. "Nursing Students Studying Physiology within a Flipped Classroom, Self-Regulation and Off-Campus Activities." Nurse Education in Practice 35: 55-62. doi:10.1016/j.nepr.2019.01.004.

Bishop, Jacob Lowell, and Matthew A. Verleger. 2013. "The Flipped Classroom: A Survey of the Research." Proceedings of the Annual Meetings of the American Society for Engineering Education 30 (9): 1-18.

Blau, Ina, and Tamar Shamir-Inbal. 2017. "Re-Designed Flipped Learning Model in an Academic Course: The Role of Co-Creation and Co-Regulation." Computers \& Education 115: 69-81. doi:10.1016/j.compedu.2017.07.014.

Bloom, Benjamin S. (1956) 1984. "The 2 Sigma Problem: The Search for Methods of Group Instruction as Effective as One-to-One Tutoring." Educational Researcher 13 (6): 4-16. doi:10.2307/1175554.

Bohaty, Brenda S., Gloria J. Redford, and Cynthia C. Gadbury-Amyot. 2016. "Flipping the Classroom: Assessment of Strategies to Promote Student-Centered, Self-Directed Learning in a Dental School Course in Pediatric Dentistry." Journal of Dental Education 80 (11): 13191327. doi:10.1002/j.0022-0337.2016.80.11.tb06217.x.

Bokosmaty, Rena, Adam Bridgeman, and Meloni Muir. 2019. "Using a Partially Flipped Learning Model to Teach First Year Undergraduate Chemistry." Journal of Chemical Education 96 (4): 629-639. doi:10.1021/acs.jchemed.8b00414. 
Bonwell, Charles C., and James A. Eison. 1991. Active Learning: Creating Excitement in the Classroom. 1991 ASHE-ERIC Higher Education Reports. Washington, DC: ERIC Clearinghouse on Higher Education.

Brown, Charles A., Kreag Danvers, and David T. Doran. 2016. "Student Perceptions on Using Guided Reading Questions to Motivate Student Reading in the Flipped Classroom." Accounting Education 25 (3): 256-271. doi:10.1080/09639284.2016.1165124.

Buil-Fabrega, Marian, Matilde Martínez Casanovas, Noemí Ruiz-Munzón, and Walter Leal Filho. 2019. "Flipped Classroom as an Active Learning Methodology in Sustainable Development Curricula." Sustainability (Switzerland) 11 (17): 4577. doi:10.3390/su11174577.

Burke, Alison S., and Brian Fedorek. 2017. "Does 'Flipping' Promote Engagement?: A Comparison of a Traditional, Online, and Flipped Class." Active Learning in Higher Education 18 (1): 11-24. doi:10.1177/1469787417693487.

Butzler, Kelly B. 2016. "The Synergistic Effects of Self-Regulation Tools and the Flipped Classroom." Computers in the Schools 33 (1): 11-23. doi:10.1080/07380569.2016.1137179.

Çakiroglu, Ünal, and Mücahit Öztürk. 2017. "Flipped Classroom with Problem Based Activities: Exploring Self-Regulated Learning in a Programming Language Course." Educational Technology \& Society 20 (1): 337-349.

Canelas, Dorian A., Jennifer L. Hill, and Andrea Novicki. 2017. "Cooperative Learning in Organic Chemistry Increases Student Assessment of Learning Gains in Key Transferable Skills.” Chemistry Education Research and Practice 18 (3): 441-456. doi:10.1039/c7rp00014f.

Carr-Chellman, Alison A., and Charles M. Reigeluth. 2009. Instructional-Design Theories and Models: Building a Common Knowledge-Base. Vol. 1, Instructional-Design Theories and Models. New York: Routledge.

Chaplin, Susan. 2009. "Assessment of the Impact of Case Studies on Student Learning Gains in an Introductory Biology Course.” Journal of College Science Teaching 39 (1): 72-79.

Chen, Liwen, Tung-Liang Chen, and Nian-Shing Chen. 2015. "Students' Perspectives of Using Cooperative Learning in a Flipped Statistics Classroom.” Australasian Journal of Educational Technology 31 (6): 621-640. doi:10.14742/ajet.1876.

Chen, Pei-Ying, and Gwo Jen Hwang. 2018. "An IRS-Facilitated Collective Issue-Quest Approach to Enhancing Students' Learning Achievement, Self-Regulation and Collective Efficacy in Flipped Classrooms.” British Journal of Educational Technology. doi: 10.1111/bjet.12690.

Chen, Mei-Rong Alice, Gwo-Jen Hwang, and Yu-Ying Chang. 2019. "A Reflective ThinkingPromoting Approach to Enhancing Graduate Students' Flipped Learning Engagement, Participation Behaviors, Reflective Thinking and Project Learning Outcomes." British Journal of Educational Technology 50 (5): 2288-2307. doi: 10.1111/bjet.12823.

Cheng, Li, Albert D. Ritzhaupt, and Pavlo Antonenko. 2019. "Effects of the Flipped Classroom Instructional Strategy on Students' Learning Outcomes: A Meta-Analysis." Educational Technology Research and Development 67 (4): 793-824. doi:10.1007/s11423-018-9633-7.

Chew, Esyin, Lim Jen Nee Jones, and Scott Wordley. 2018. “Flipping or Flapping?' Investigating Engineering Students' Experience in Flipped Classrooms." On the Horizon 26 (4): 307-316. doi:10.1108/OTH-04-2017-0014.

Chiang, Yu Hung, and Hei-Chia Wang. 2015. "Effects of the In-Flipped Classroom on the Learning Environment of Database Engineering." International Journal of Engineering Education 31 (2): 454-460.

Chis, Adriana E., Arghir-Nicolae Moldovan, Lisa Murphy, Pramod Pathak, and Muntean Hava. 2018. "Investigating Flipped Classroom and Problem-Based Learning in a Programming Module for Computing Conversion Course." Journal of Educational Technology \& Society 21 (4): 232-247.

Christiansen, Michael A., Alyssia M. Lambert, Louis S. Nadelson, Kami M. Dupree, and Trish A. Kingsford. 2017. "In-Class Versus At-Home Quizzes: Which is Better? A Flipped Learning Study in a Two-Site Synchronously Broadcast Organic Chemistry Course." Journal of Chemical Education 94 (2): 157-163. doi:10.1021/acs.jchemed.6b00370.

Clark, Renee, Autar Kaw, Yingyan Lou, Andrew Scott, and Mary Besterfield-Sacre. 2018. "Evaluating Blended and Flipped Instruction in Numerical Methods at Multiple Engineering 
Schools." International Journal for the Scholarship of Teaching and Learning 12 (1), doi:0.20429/ ijsotl.2018.120111.

Colquhoun, Heather L., Danielle Levac, Kelly K. O’Brien, Sharon Straus, Andrea C. Tricco, Laure Perrier, Monika Kastner, and David Moher. 2014. "Scoping Reviews: Time for Clarity in Definition, Methods, and Reporting." Journal of Clinical Epidemiology 67 (12): 1291-1294. doi:10.1016/j.jclinepi.2014.03.013.

Conner, Nathan W., Eric D. Rubenstein, Cathy A. DiBenedetto, Christopher T. Stripling, T. Grady Roberts, and Nicole L. P. Stedman. 2014. "Examining Student Perceptions of Flipping an Agricultural Teaching Methods Course.” Journal of Agricultural Education 55 (5): 65-77. doi:10.5032/jae.2014.05065.

Covill, Laura, and Jason Cook. 2019. "Comparison of Academic Performance in Traditional and Flipped Classrooms and Students' Attitudes of the Flipped Experience." Journal of Allied Health 48 (1): e-e7.

Crouch, Catherine H., and Eric Mazur. 2001. "Peer Instruction: Ten Years of Experience and Results.” American Journal of Physics 69 (9): 970-977. doi:10.1119/1.1374249.

Das, Ashish K., Quynh T. Nguyen, An T. Nguyen, Milton Nomikoudis, and Dung Ha Van. 2019. "Course Redesign to Incorporate Flipped Delivery: A Business Degree Case in Vietnam." Issues in Educational Research 29 (2): 363-383.

Day, Leslie J. 2018. “A Gross Anatomy Flipped Classroom Effects Performance, Retention, and Higher-Level Thinking in Lower Performing Students.” Anatomical Sciences Education 11 (6): 565-574. doi:10.1002/ase.1772.

Dehghanzadeh, Shadi, and Fateme Jafaraghaee. 2018. "Comparing the Effects of Traditional Lecture and Flipped Classroom on Nursing Students' Critical Thinking Disposition: A QuasiExperimental Study.” Nurse Education Today 71: 151-156. doi:10.1016/j.nedt.2018.09.027.

DeLozier, Sarah J., and Matthew G. Rhodes. 2017. "Flipped Classrooms: A Review of Key Ideas and Recommendations for Practice.” Educational Psychology Review 29 (1): 141-151. doi:10.1007/ s10648-015-9356-9.

de Novais, André Seixas, Messias Borges Silva, and Jr Jorge Muniz. 2017. "Strengths, Limitations and Challenges in the Implementation of Active Learning in an Undergraduate Course of Logistics Technology." International Journal of Engineering Education 33 (3): 1060-1069.

Deri, Melissa A., Pamela Mills, and Donna McGregor. 2018. "Structure and Evaluation of a Flipped General Chemistry Course as a Model for Small and Large Gateway Science Courses at an Urban Public Institution." Journal of College Science Teaching 47 (3): 68-77. doi:10. 2505/4/jcst18_047_03_68.

Deslauriers, Louis, Logan S. McCarty, Kelly Miller, Kristina Callaghan, and Greg Kestin. 2019. "Measuring Actual Learning Versus Feeling of Learning in Response to Being Actively Engaged in the Classroom." Proceedings of the National Academy of Sciences 116 (39): 19251-19257. doi:10.1073/pnas.1821936116.

Drake, John R. 2012. "A Critical Analysis of Active Learning and an Alternative Pedagogical Framework for Introductory Information Systems Courses." Journal of Information Technology Education 11: 39-52.

Eichler, Jack F., and Junelyn Peeples. 2016. "Flipped Classroom Modules for Large Enrollment General Chemistry Courses: A Low Barrier Approach to Increase Active Learning and Improve Student Grades." Chemistry Education Research and Practice 17 (1): 197-208. doi:10.1039/C5RP00159E.

Engbers, Trent. 2019. "Between Lecture and Flipped: The Use of "Labs" in the Public Administration Classroom.” Teaching Public Administration 37 (3): 312-326. doi:10.1177/ 0144739419858692.

Eryilmaz, Meltem, and Ceyhan Cigdemoglu. 2019. "Individual Flipped Learning and Cooperative Flipped Learning: Their Effects on Students' Performance, Social, and Computer Anxiety.” Interactive Learning Environments 27 (4): 432-442. doi:10.1080/10494820.2018.1522652.

Evans, Leda, Melodee L. Vanden Bosch, Susan Harrington, Nancy Schoofs, and Cynthia Coviak. 2019. "Flipping the Classroom in Health Care Higher Education: A Systematic Review." Nurse Educator 44 (2): 74-78. doi:10.1097/NNE.0000000000000554. 
Fan, Xiaoian. 2018. "Research on Oral English Flipped Classroom Project-Based Teaching Model Based on Cooperative Learning in China.” Kuram ve Uygulamada Egitim Bilimleri 18 (5): $1988-$ 1998. doi:10.12738/estp.2018.5.098.

Fauzi, Sherina Shahnaz Mohamed, and Raja Maznah Raja Hussain. 2016. "Designing Instruction for Active and Reflective Learners in the Flipped Classroom.” Malaysian Journal of Learning and Instruction 13 (2): 147-173. doi:10.32890/mjli2016.13.2.6.

Fidalgo-Blanco, Ángel, María Luis Sein-Echaluce, and Francisco José García-Peñalvo. 2018. "Ontological Flip Teaching: A Flip Teaching Model Based on Knowledge Management." Universal Access in the Information Society 17 (3): 475-489. doi:10.1007/s10209-017-0556-6.

Finne, Max. 2018. "Improving University Teaching: A Professional Service Operation Perspective.” International Journal of Operations and Production Management 38 (9): 17651795. doi:10.1108/IJOPM-12-2016-0729.

Foldnes, Njål. 2016. "The Flipped Classroom and Cooperative Learning: Evidence from a Randomised Experiment.” Active Learning in Higher Education 17 (1): 39-49. doi:10.1177/1469787415616726.

Ford, Dayton. 2019. "A Three-Year Retrospective Analysis Comparing Student Retention of Human Physiology Concepts in Flipped, Lecture, and Two-Stage Cooperative Testing Classrooms." Journal of College Science Teaching 49 (1): 59-63.

Foster, Gillian, and Sigrid Stagl. 2018. "Design, Implementation, and Evaluation of an Inverted (Flipped) Classroom Model Economics for Sustainable Education Course." Journal of Cleaner Production 183: 1323-1336. doi:10.1016/j.jclepro.2018.02.177.

Framework for 21st Century Learning. 2019. “The Partnership for 21st Century Skills.” Accessed April 25 2021. https://www.battelleforkids.org/networks/p21/frameworks-resources.

Freeman, Scott, Sarah L. Eddy, Miles McDonough, Michelle K. Smith, Nnadozie Okoroafor, Hannah Jordt, and Mary Pat Wenderoth. 2014. "Active Learning Increases Student Performance in Science, Engineering, and Mathematics." Proceedings of the National Academy of Sciences 111 (23): 8410-8415. doi:10.1073/pnas.1319030111.

Freeman, Scott, Eileen O’Connor, John W. Parks, Matthew Cunningham, David Hurley, David Haak, Clarissa Dirks, and Mary Pat Wenderoth. 2007. "Prescribed Active Learning Increases Performance in Introductory Biology.” CBE-Life Sciences Education 6 (2): 132-139. doi:10. 1187/cbe.06-09-0194.

Galway, Lindsay P., Kitty K. Corbett, Timothy K. Takaro, Kate Tairyan, and Erica Frank. 2014. “A Novel Integration of Online and Flipped Classroom Instructional Models in Public Health Higher Education.” BMC Medical Education 14: 181. doi:10.1186/1472-6920-14-181.

Garnjost, Petra, and Leanna Lawter. 2019. "Undergraduates' Satisfaction and Perceptions of Learning Outcomes Across Teacher- and Learner-Focused Pedagogies." International Journal of Management Education 17 (2): 267-275. doi:10.1016/j.ijme.2019.03.004.

Gayathri, H., and Kannan Vijayarani. 2017. “Flipping: A Strategy for Efficient Learning in Today's Classroom.” International Journal of Pedagogical Innovations 5 (1): 72-89.

Giuliano, Christopher Alan, and Lynette R. Moser. 2016. "Evaluation of a Flipped Drug Literature Evaluation Course." American Journal of Pharmaceutical Education 80 (4): 1-8. doi:10.5688/ ajpe80466.

Hake, Richard R. 1998. "Interactive-Engagement Versus Traditional Methods: A Six-ThousandStudent Survey of Mechanics Test Data for Introductory Physics Courses." American Journal of Physics 66 (1): 64-74. doi:10.1119/1.18809.

Halili, Siti Hajar, Shukri Sulaiman, Hamidah Sulaiman, and Rafiza Razak. 2019. "Exploring Students' Learning Styles in Using Mobile Flipped Classroom." International and Multidisciplinary Journal of Social Sciences 8 (2): 105-125. doi:10.17583/rimcis.2019.4070.

Harris, Nicolette, and Cailee E. Welch Bacon. 2019. "Developing Cognitive Skills Through Active Learning: A Systematic Review of Health Care Professions." Athletic Training Education Journal 14 (2): 135-148. doi:10.4085/1402135.

Harrison, David J., Laurel Saito, Nancy Markee, and Serge Herzog. 2017. “Assessing the Effectiveness of a Hybrid-Flipped Model of Learning on Fluid Mechanics Instruction: Overall Course Performance, Homework, and Far- and Near-Transfer of Learning." European Journal of Engineering Education 42 (6): 712-728. doi:10.1080/03043797.2016.1218826. 
He, Wenliang, Amanda Holton, Hengrui Gu, Mark Warschauer, and George Farkas. 2019. "Differentiated Impact of Flipped Instruction: When Would Flipped Instruction Work or Falter?" International Journal of Teaching and Learning in Higher Education 31 (1): 32-49.

Hew, Khe Foon, and Chung Kwan Lo. 2018. "Flipped Classroom Improves Student Learning in Health Professions Education: A Meta-Analysis.” BMC Medical Education 18 (1): 38. doi:10. 1186/s12909-018-1144-z.

Ho, Janet. 2019. "Gamifying the Flipped Classroom: How to Motivate Chinese ESL Learners?" Innovation in Language Learning and Teaching. doi:10.1080/17501229.2019.1614185.

Howe, Neil, and William Strauss. 2003. Millennials go to College: Strategies for a New Generation on Campus: Recruiting and Admissions, Campus Life, and the Classroom. Wachington, DC: American Association of Collegiate Registrars and Admissions Officers.

$\mathrm{Hu}$, Xiaolei, Hengyan Zhang, Yuan Song, Chenchen Wu, Qingqing Yang, Z Zhaoming Shi, Xiaomei Zhang, and Weidong Chen. 2019. "Implementation of Flipped Classroom Combined with Problem-Based Learning: An Approach to Promote Learning About Hyperthyroidism in the Endocrinology Internship.” BMC Medical Education 19 (1), doi:10. 1186/s12909-019-1714-8.

Huguet, Carme, Jillian Pearse, Leslie F. Noè, Diego M. Valencia, Nataly Castillo Ruiz, Alexa Jimenez Heredia, and Mónica Andrea Patiño Avedaño. 2020. "Improving the Motivation of Students in a Large Introductory Geoscience Course Through Active Learning." Journal of Geoscience Education 68 (1): 20-32. doi:10.1080/10899995.2019.1588489.

Hung, Hsiu Ting. 2015. "Flipping the Classroom for English Language Learners to Foster Active Learning.” Computer Assisted Language Learning 28 (1): 81-96. doi:10.1080/09588221.2014. 967701.

Hwang, Gwo Jen, and Pei Ying Chen. 2019. "Effects of a Collective Problem-Solving PromotionBased Flipped Classroom on Students' Learning Performances and Interactive Patterns." Interactive Learning Environments. doi:10.1080/10494820.2019.1568263.

Jensen, Jamie L., Emily A. Holt, Jacob B. Sowards, Ogden Heath, and Richard E. West. 2018. "Investigating Strategies for Pre-Class Content Learning in a Flipped Classroom." Journal of Science Education \& Technology 27 (6): 523-535. doi:10.1007/s10956-018-9740-6.

Jensen, Jamie L., Tyler A. Kummer, and Patricia D. D. M. Godoy. 2015. "Improvements from a Flipped Classroom May Simply be the Fruits of Active Learning." CBE Life Sciences Education 14 (1): 1-12. doi:10.1187/cbe.14-08-0129.

Jones, Jason P., David A. McConnell, Jennifer L. Wiggen, and John Bedward. 2019. "Effects of Classroom 'Flipping' on Content Mastery and Student Confidence in an Introductory Physical Geology Course.” Journal of Geoscience Education 67 (3): 195-210. doi:10.1080/ 10899995.2019.1568854.

Joseph, Sonu, and Sherine Joy. 2019. "Learning Attitudes and Resistance to Learning Language in Engineering Students." International Journal of Innovative Technology and Exploring Engineering 8 (10): 2085-2091. doi:10.35940/ijitee.J9336.0881019.

Jovanovic, Jelena, Negin Mirriahi, Dragan Gašević, Shane Dawson, and Abelardo Pardo. 2019. "Predictive Power of Regularity of Pre-Class Activities in a Flipped Classroom." Computers and Education 134: 156-168. doi:10.1016/j.compedu.2019.02.011.

Juárez, Gilberto Huesca, and Linda Margarita Medina Herrera. 2019. "Learning Gain Study in a Strategy of Flipped Learning in the Undergraduate Level." International Journal on Interactive Design and Manufacturing (IJIDeM) 13 (4): 1245-1258. doi:10.1007/s12008-01900594-3.

Kantanen, Helena, Jonna Koponen, Erkko Sointu, and Teemu Valtonen. 2019. "Including the Student Voice: Experiences and Learning Outcomes of a Flipped Communication Course." Business and Professional Communication Quarterly 82 (3): 337-356. doi:10.1177/ 2329490619833397.

Kaw, Autar, Renee Clark, Eleonora Delgado, and Nicholas Abate. 2019. "Analyzing the Use of Adaptive Learning in a Flipped Classroom for Preclass Learning." Computer Applications in Engineering Education 27 (3): 663-678. doi:10.1002/cae.22106. 
Kay, Robin Holding, Thom MacDonald, and Maurice DiGiuseppe. 2019. "A Comparison of Lecture-Based, Active, and Flipped Classroom Teaching Approaches in Higher Education." Journal of Computing in Higher Education 31 (3): 449-471. doi:10.1007/s12528-018-9197-x.

Kenwright, Diane, Wei Dai, Emma Osborne, Tehmina Gladman, Peter Gallagher, and Rebecca Grainger. 2017. “'Just Tell Me What I Need to Know to Pass the Exam!' Can Active Flipped Learning Overcome Passivity?” Asia Pacific Scholar 2 (1): 1-6. doi:10.29060/TAPS.2017-2-3/ OA1023.

Khanova, Julia, Jacqueline E. McLaughlin, Denise H. Rhoney, Mary T. Roth, and Suzanne Harris. 2015a. "Student Perceptions of a Flipped Pharmacotherapy Course." American Journal of Pharmaceutical Education 79 (9): 1-8. doi:10.5688/ajpe799140.

Khanova, Julia, Mary T. Roth, Jo Ellen Rodgers, and Jacqueline E. McLaughlin. 2015b. "Student Experiences Across Multiple Flipped Courses in a Single Curriculum." Medical Education 49 (10): 1038-1048. doi:10.1111/medu.12807.

Kim, Dohun. 2017. "Flipped Interpreting Classroom: Flipping Approaches, Student Perceptions and Design Considerations.” Interpreter and Translator Trainer 11 (1): 38-55. doi:10.1080/ 1750399x.2016.1198180.

King, Alison. 1993. "From Sage on the Stage to Guide on the Side." College Teaching 41 (1): 30-35. doi:10.1080/87567555.1993.9926781.

Knight, Jennifer K., and William B. Wood. 2005. “Teaching More by Lecturing Less.” Cell Biology Education 4 (4): 298-310. doi:10.1187/05-06-0082.

Koh, Joyce Hwee Ling. 2019. "Four Pedagogical Dimensions for Understanding Flipped Classroom Practices in Higher Education: A Systematic Review." Educational Sciences: Theory \& Practice 19 (4): 14-33. doi:10.12738/estp.2019.4.002.

Krathwohl, David R. 2002. "A Revision of Bloom's Taxonomy: An Overview.” Theory Into Practice 41 (4): 212-218. doi:10.1207/s15430421tip4104_2.

Kühl, Susanne J., Achim Schneider, Hans A. Kestler, Matthias Toberer, Michael Kühl, and Martin R. Fischer. 2019. "Investigating the Self-Study Phase of an Inverted Biochemistry ClassroomCollaborative Dyadic Learning Makes the Difference.” BMC Medical Education 19: 1. doi:10. 1186/s12909-019-1497-y.

Kwon, Jung Eon, and Hyung Rok Woo. 2018. “The Impact of Flipped Learning on Cooperative and Competitive Mindsets." Sustainability (Switzerland) 10 (1): 79. doi:10.3390/su10010079.

Låg, Torstein, and Rannveig Grøm Sæle. 2019. "Does the Flipped Classroom Improve Student Learning and Satisfaction? A Systematic Review and Meta-Analysis." AERA Open 5 (3): 1-17. doi:10.1177/2332858419870489.

Lage, Maureen J., Glenn J. Platt, and Michael Treglia. 2000. "Inverting the Classroom: A Gateway to Creating an Inclusive Learning Environment." The Journal of Economic Education 31 (1): 30 43. doi:10.1080/00220480009596759.

Lally, Diane, and Cory Forbes. 2019. "Modelling Water Systems in an Introductory Undergraduate Course: Students' Use and Evaluation of Data-Driven, Computer-Based Models.” International Journal of Science Education 41 (14): 1999-2023. doi:10.1080/09500693.2019.1657252.

Lambach, Daniel, and Caroline Kärger. 2019. "Inverting the Classroom in Large-Enrollment Classes: A Beginner's Guide.” Journal of Political Science Education. doi:10.1080/15512169. 2019.1664907.

Lambach, Daniel, Caroline Kärger, and Achim Goerres. 2017. "Inverting the Large Lecture Class: Active Learning in an Introductory International Relations Course." European Political Science 16 (4): 553-569. doi:10.1057/s41304-016-0078-3.

le-Roux, Ingrid, and Lynette Nagel. 2018. "Seeking the Best Blend for Deep Learning in a Flipped Classroom-Viewing Student Perceptions Through the Community of Inquiry Lens." International Journal of Educational Technology in Higher Education 15 (1), doi:10.1186/ s41239-018-0098-x.

Leatherman, Judith L., and Lacy M. Cleveland. 2019. "Student Exam Performance in Flipped Classroom Sections is Similar to That in Active Learning Sections, and Satisfaction with the Flipped Classroom Hinges on Attitudes Toward Learning from Videos." Journal of Biological Education 54 (3), doi:10.1080/00219266.2019.1575266. 
Lederman, Norman G., and Judith S. Lederman. 2015. "What is a Theoretical Framework? A Practical Answer." Journal of Science Teacher Education 26: 593-597. doi:10.1007/s10972015-9443-2.

Lee, Jieun, and Curtis J. Bonk. 2019. "Integrating Flipped Learning with Team-Based Learning in a Pre-Service Teacher Education Course: Experiences and Outcomes." International Journal on E-Learning 18 (1): 5-29.

Lee, Namhun, Lee W. Lee, and Jacob Kovel. 2016. “An Experimental Study of Instructional Pedagogies to Teach Math-Related Content Knowledge in Construction Management Education." International Journal of Construction Education and Research 12 (4): 255-269. doi:10.1080/15578771.2016.1141440.

Lento, Camillo. 2016. "Promoting Active Learning in Introductory Financial Accounting Through the Flipped Classroom Design." Journal of Applied Research in Higher Education 8 (1): 72-87. doi:10.1108/jarhe-01-2015-0005.

Lento, Camillo. 2017. "Incorporating Whiteboard Voice-Over Video Technology Into the Accounting Curriculum.” Issues in Accounting Education 32 (3): 153-168. doi:10.2308/iace51584 .

Lewis, Catherine E., David C. Chen, and Anju Relan. 2018. "Implementation of a Flipped Classroom Approach to Promote Active Learning in the Third-Year Surgery Clerkship." American Journal of Surgery 215 (2): 298-303. doi:10.1016/j.amjsurg.2017.08.050.

Lin, Hui-Chen, and Gwo-Jen Hwang. 2019. "Research Trends of Flipped Classroom Studies for Medical Courses: A Review of Journal Publications from 2008 to 2017 Based on the Technology-Enhanced Learning Model.” Interactive Learning Environments 27 (8): 10111027. doi:10.1080/10494820.2018.1467462.

Long, Taotao, John Cummins, and Michael Waugh. 2017. "Use of the Flipped Classroom Instructional Model in Higher Education: Instructors' Perspectives." Journal of Computing in Higher Education 29 (2): 179-200. doi:10.1007/s12528-016-9119-8.

Long, Taotao, John Cummins, and Michael Waugh. 2020. "To Flip or Not in Higher Education: A Tale of Three Instructors." Asia-Pacific Education Researcher 29: 201-212. doi:10.1007/s40299019-00470-4.

Long, Taotao, Joanne Logan, and Michael Waugh. 2016. "Students' Perceptions of the Value of Using Videos as a Pre-Class Learning Experience in the Flipped Classroom.” TechTrends: Linking Research and Practice to Improve Learning 60 (3): 245-252. doi:10.1007/s11528-0160045-4.

Lucke, Terry, K. Peter Dunn, and Michael Christie. 2017. “Activating Learning in Engineering Education Using ICT and the Concept of 'Flipping the Classroom'." European Journal of Engineering Education 42 (1): 45-57. doi:10.1080/03043797.2016.1201460.

Lumpkin, Angela, and Rebecca M. Achen. 2015. "Flipping a Class: Active Learning and More of It.” Sport Management Education Journal 9 (2): 79-90. doi:10.1123/smej.2014-0042.

Lundin, Mona, Annika Bergviken Rensfeldt, Thomas Hillman, Annika Lantz-Andersson, and Louise Peterson. 2018. "Higher Education Dominance and Siloed Knowledge: A Systematic Review of Flipped Classroom Research." International Journal of Educational Technology in Higher Education 15 (1): 20. doi:10.1186/s41239-018-0101-6.

Maheshwari, Prateek, and Nitin Seth. 2019. "Effectiveness of Flipped Classrooms: A Case of Management Education in Central India." International Journal of Educational Management 33 (5): 860-885. doi:10.1108/IJEM-10-2017-0282.

Mason, Greg S., Teodora Rutar Shuman, and Kathleen E. Cook. 2013. "Comparing the Effectiveness of an Inverted Classroom to a Traditional Classroom in an Upper-Division Engineering Course.” IEEE Transactions on Education 56 (4): 430-435. doi:10.1109/TE.2013. 2249066.

Matthew, Susan M., Regina M. Schoenfeld-Tacher, Jared A. Danielson, and Sheena M. Warman. 2019. "Flipped Classroom Use in Veterinary Education: A Multinational Survey of Faculty Experiences." Journal of Veterinary Medical Education 46 (1): 97-107. doi:10.3138/jvme. 0517-058r1. 
McCallum, Shelly, Janel Schultz, Kristen Sellke, and Jason Spartz. 2015. “An Examination of the Flipped Classroom Approach on College Student Academic Involvement.” International Journal of Teaching and Learning in Higher Education 27 (1): 42-55.

McCubbins, O. P., Thomas H. Paulsen, and Ryan Anderson. 2018. "Examining Student Perceptions of Their Experience in a TBL Formatted Capstone Course." Journal of Agricultural Education 59 (1): 135-152. doi:10.5032/jae.2018.01135.

McLaughlin, Jacqueline E., LaToya M. Griffin, Denise A. Esserman, Christopher A. Davidson, Dylan M. Glatt, Mary T. Roth, Nastaran Gharkholonarehe, and Russell J. Mumper. 2013. "Pharmacy Student Engagement, Performance, and Perception in a Flipped Satellite Classroom." American Journal of Pharmaceutical Education 77 (9): 1-8. doi:10.5688/ ajpe779196.

Moher, David, Alessandro Liberati, Jennifer Tetzlaff, and Douglas G Altman. 2009. "Preferred Reporting Items for Systematic Reviews and Meta-Analyses: The PRISMA Statement." BMJ 339: b2535. doi:10.1136/bmj.b2535.

Mooring, Suazette R., Chloe E. Mitchell, and Nikita L. Burrows. 2016. "Evaluation of a Flipped, Large-Enrollment Organic Chemistry Course on Student Attitude and Achievement.” Journal of Chemical Education 93 (12): 1972-1983. doi:10.1021/acs.jchemed.6b00367.

Moraros, John, Adiba Islam, Stan Yu, Ryan Banow, and Barbara Schindelka. 2015. "Flipping for Success: Evaluating the Effectiveness of a Novel Teaching Approach in a Graduate Level Setting." BMC Medical Education 15 (1), doi:10.1186/s12909-015-0317-2.

Morosan, Christian, Mary Dawson, and Elizabeth Ann Whalen. 2017. "Using Active Learning Activities to Increase Student Outcomes in an Information Technology Course." Journal of Hospitality and Tourism Education 29 (4): 147-157. doi:10.1080/10963758.2017.1382369.

Motameni, Reza. 2018. "The Combined Impact of the Flipped Classroom, Collaborative Learning, on Students' Learning of key Marketing Concepts." Journal of University Teaching and Learning Practice 15 (3): 19.

Mulcare, Daniel M., and Allan Shwedel. 2017. “Transforming Bloom’s Taxonomy Into Classroom Practice: A Practical Yet Comprehensive Approach to Promote Critical Reading and Student Participation.” Journal of Political Science Education 13 (2): 121-137. doi:10.1080/15512169. 2016.1211017.

Muldrow, Karen. 2013. "A New Approach to Language Instruction: Flipping the Classroom.” The Language Educator 11: 28-31.

Munir, Muhammad Tajammal, Saeid Baroutian, Brent R. Young, and Susan Carter. 2018. "Flipped Classroom with Cooperative Learning as a Cornerstone." Education for Chemical Engineers 23: 25-33. doi:10.1016/j.ece.2018.05.001.

Narendran, Roshni, Shamika Almeida, Rebecca Coombes, Geraldine Hardie, and Eunice Quintana-Smark. 2018. "The Role of Self-Determination Theory in Developing Curriculum for Flipped Classroom Learning: A Case Study of First-Year Business Undergraduate Course." Journal of University Teaching and Learning Practice 15 (5): 21.

Ng, Eugenia M. W. 2019. "Fostering Self and Peer Learning Inside and Outside the Classroom through the Flipped Classroom Approach for Postgraduate Students." Issues in Informing Science \& Information Technology 16: 51-59. doi:10.28945/4290.

Notaros, Branislav M., Ryan McCullough, Pranav S. Athalye, and Anthony A. Maclejewski. 2019. "New Partially Flipped Electromagnetics Classroom Approach Using Conceptual Questions." International Journal of Engineering Education 35 (4): 1215-1223.

O'Flaherty, Jacqueline, and Craig Phillips. 2015. “The Use of Flipped Classrooms in Higher Education: A Scoping Review." The Internet and Higher Education 25: 85-95. doi:10.1016/j. iheduc.2015.02.002.

Oliván Blázquez, Bárbara, Barbara Masluk, Santiago Gascon, Ricardo Fueyo Díaz, Alejandra Aguilar-Latorre, Isabel Artola Magallón, and Rosa Magallón Botaya. 2019. "The Use of Flipped Classroom As An Active Learning Approach Improves Academic Performance in Social Work: A Randomized Trial in a University.” PLoS ONE 14 (4): 1-15. doi:10.1371/ journal.pone.0214623. 
Olusegun, Steve. 2015. "Constructivism Learning Theory: A Paradigm for Teaching and Learning." IOSR Journal of Research \& Method in Education 5 (6): 66-70. doi:10.9790/738805616670.

Osman, Siti Zuraidah, Rozinah Jamaludin, and Nor Fathimah Fathil. 2016. “An Analysis of Using Online Video Lecture on Learning Outcome: The Mediating Role of Student Interaction and Student Engagement." Journal of Education and e-Learning Research 3 (2): 57-64.

Overmyer, Jerry. 2015. "Research on Flipping College Algebra: Lessons Learned and Practical Advice for Flipping Multiple Sections.” PRIMUS 25 (9): 792-802. doi:10.1080/10511970.2015. 1045572.

Panadero, Ernesto. 2017. “A Review of Self-Regulated Learning: Six Models and Four Directions for Research.” Frontiers in Psychology 8: 422. doi:10.3389/fpsyg.2017.00422.

Pejuan, Arcadi, and Josefina Antonijuan. 2019. "Independent Learning as Class Preparation to Foster Student-Centred Learning in First-Year Engineering Students.” Research in PostCompulsory Education 24 (4): 375-400. doi:10.1080/13596748.2019.1584447.

Peters, Travis, Elgin Johnston, Heather Bolles, Craig Ogilvie, Alexis Knaub, and Thomas Holme. 2019. "Benefits to Students of Team-Based Learning in Large Enrollment Calculus." PRIMUS. doi:10.1080/10511970.2018.1542417.

Piaget, Jean. 1957. Construction of Reality in the Child. London: Routledge \& Kegan Paul.

Porcaro, Pauline A., Denise E. Jackson, Patricia M. McLaughlin, and Cindy J. O’Malley. 2016. "Curriculum Design of a Flipped Classroom to Enhance Haematology Learning." Journal of Science Education and Technology 25 (3): 345-357. doi:10.1007/s10956-015-9599-8.

Prashar, Anupama. 2015. "Assessing the Flipped Classroom in Operations Management: A Pilot Study.” Journal of Education for Business 90 (3): 126-138. doi:10.1080/08832323.2015.1007904.

Price, Charlotte, and Maria Walker. 2019. "Improving the Accessibility of Foundation Statistics for Undergraduate Business and Management Students Using a Flipped Classroom." Studies in Higher Education. doi:10.1080/03075079.2019.1628204.

Prince, Michael. 2004. "Does Active Learning Work? A Review of the Research." Journal of Engineering Education 93 (3): 223-231. doi:10.1002/j.2168-9830.2004.tb00809.x.

Qiang, Jian. 2019. "Effects of Digital Flipped Classroom Teaching Method Integrated Cooperative Learning Model on Learning Motivation and Outcome.” Electronic Library 37 (5): 842-859. doi:10.1108/EL-02-2019-0024.

Raman, Raghu. 2015. "Flipped Labs as a Smart ICT Innovation: Modeling Its Diffusion among Interinfluencing Potential Adopters." Advances in Intelligent Systems and Computing 320: 621-631. doi:10.1007/978-3-319-11218-3_55.

Ramlo, Susan. 2015. "Student Views About a Flipped Physics Course: A Tool for Program Evaluation and Improvement." Research in the Schools 22 (1): 44-59.

Rau, Martina A., Kristopher Kennedy, Lucas Oxtoby, Mark Bollom, and W. Moore John. 2017. "Unpacking 'Active Learning': A Combination of Flipped Classroom and Collaboration Support Is More Effective but Collaboration Support Alone Is Not." Journal of Chemical Education 94 (10): 1406-1414.

Reddan, Gregory, Brenton McNally, and Janine Chipperfield. 2016. "Flipping the Classroom in an Undergraduate Sports Coaching Course.” International Journal of Sports Science and Coaching 11 (2): 270-278. doi:10.1177/1747954116637497.

Riddell, Jeff, Paul Jhun, Cha-Chi Fung, James Comes, Stacy Sawtelle, Ramin Tabatabai, Daniel Joseph, et al. 2017. "Does the Flipped Classroom Improve Learning in Graduate Medical Education?" Journal of Graduate Medical Education 9 (4): 491-496. doi:10.4300/JGME-D-16-00817.1.

Robert, Jenay, E. Lewis Scott, Razanne Oueini, and Andrea Mapugay. 2016. "Coordinated Implementation and Evaluation of Flipped Classes and Peer-Led Team Learning in General Chemistry." Journal of Chemical Education 93 (12): 1993-1998. doi:10.1021/acs.jchemed. $6 \mathrm{~b} 00395$.

Rodríguez, Gemma, Juana Díez, Nahshon Pérez, Josep-Eladi Baños, and Mar Carrió. 2019. "Flipped Classroom: Fostering Creative Skills in Undergraduate Students of Health Sciences." Thinking Skills and Creativity 33. doi:10.1016/j.tsc.2019.100575. 
Røe, Yngve, Michael Rowe, Nina B. Ødegaard, Hilde Sylliaas, and Tone Dahl-Michelsen. 2019. "Learning with Technology in Physiotherapy Education: Design, Implementation and Evaluation of a Flipped Classroom Teaching Approach.” BMC Medical Education 19 (1): 291. doi:10.1186/s12909-019-1728-2.

Romero-García, Carmen, Olga Buzón-García, and Javier Touron. 2019. “The Flipped Learning Model in Online Education for Secondary Teachers." Journal of Technology and Science Education 9 (2): 109-121. doi:10.3926/jotse.435.

Sánchez-Azqueta, Carlos, Esther Cascarosa, Santiago Celma, Cecilia Gimeno, and Concepción Aldea. 2019. "Application of a Flipped Classroom for Model-Based Learning in Electronics." International Journal of Engineering Education 35 (3): 938-946.

Sankey, Michael, and Lynne Hunt. 2014. "Flipped University Classrooms: Using Technology to Enable Sound Pedagogy." Journal of Cases on Information Technology 16 (2): 26-38. doi:10. 4018/jcit.2014040103.

Schneider, Bertrand, and Paulo Blikstein. 2016. "Flipping the Flipped Classroom: A Study of the Effectiveness of Video Lectures Versus Constructivist Exploration Using Tangible User Interfaces." IEEE Transactions on Learning Technologies 9 (1): 5-17. doi:10.1109/tlt.2015. 2448093.

Schwarzenberg, Pablo, Jaime Navon, Miguel Nussbaum, Mar Pérez-Sanagustin, and Daniela Caballero. 2018. "Learning Experience Assessment of Flipped Courses." Journal of Computing in Higher Education 30 (2): 237-258. doi:10.1007/s12528-017-9159-8.

Seery, Michael K. 2015. "Flipped Learning in Higher Education Chemistry: Emerging Trends and Potential Directions." Chemistry Education Research and Practice 16 (4): 758-768. doi:10.1039/ C5RP00136F.

Sfard, Anna. 1998. "On Two Metaphors for Learning and the Dangers of Choosing Just One." Educational Researcher 27 (2): 4-13.

Shatto, Bobbi, Kristine L'Ecuyer, and Jerod Quinn. 2017. "Retention of Content Utilizing a Flipped Classroom Approach.” Nursing Education Perspectives 38 (4): 206-208. doi:10.1097/01.NEP. 0000000000000138.

Shattuck, James C. 2016. "A Parallel Controlled Study of the Effectiveness of a Partially Flipped Organic Chemistry Course on Student Performance, Perceptions, and Course Completion.” Journal of Chemical Education 93 (12): 1984-1992. doi:10.1021/acs.jchemed.6b00393.

Shen, Jing. 2018. "Flipping the Classroom for Information Literacy Instruction: Considerations Towards Personalisation and Collaborative Learning." Journal of Information Literacy 12 (1): 48-67. doi:10.11645/12.1.2274.

Skagen, Darlene, Brett McCollum, Layne Morsch, and Brandon Shokoples. 2018. "Developing Communication Confidence and Professional Identity in Chemistry Through International Online Collaborative Learning." Chemistry Education Research and Practice 19 (2): 567-582. doi:10.1039/c7rp00220c.

Sletten, Sarah Rae. 2017. "Investigating Flipped Learning: Student Self-Regulated Learning, Perceptions, and Achievement in an Introductory Biology Course." Journal of Science Education and Technology 26 (3): 347-358. doi:10.1007/s10956-016-9683-8.

Smith, Kathryn J., Oliver Grundmann, and Robin Moorman Li. 2018. "The Development and Impact of Active Learning Strategies on Self-Confidence in a Newly Designed First-Year SelfCare Pharmacy Course - Outcomes and Experiences." Currents in Pharmacy Teaching and Learning 10 (4): 499-504. doi:10.1016/j.cptl.2017.12.008.

Steen-Utheim, Anna Therese, and Njål Foldnes. 2018. "A Qualitative Investigation of Student Engagement in a Flipped Classroom.” Teaching in Higher Education 23 (3): 307-324. doi:10. 1080/13562517.2017.1379481.

Stover, Sheri, and Cindra Holland. 2018. "Student Resistance to Collaborative Learning." International Journal for the Scholarship of Teaching and Learning 12 (2), doi:10.20429/ijsotl. 2018.120208.

Stover, Sheri, and M. A. Houston. 2019. "Designing Flipped-Classes to Be Taught with Limited Resources: Impact on Students' Attitudes and Learning." Journal of the Scholarship of Teaching and Learning 19 (3): 34-48. doi:10.14434/josotl.v19i2.23868. 
Strayer, Jeremy F. 2012. "How Learning in an Inverted Classroom Influences Cooperation, Innovation and Task Orientation." Learning Environments Research 15 (2): 171-193. doi:10. 1007/s10984-012-9108-4.

$\mathrm{Su}$, Chien-Yuan, and Cheng-Huan Chen. 2018. "Investigating the Effects of Flipped Learning, Student Question Generation, and Instant Response Technologies on Students' Learning Motivation, Attitudes, and Engagement: A Structural Equation Modeling." Eurasia Journal of Mathematics, Science and Technology Education 14 (6): 2453-2466. doi:10.29333/ejmste/89938.

Sun, Zhiru, Kui Xie, and Lynley H. Anderman. 2018. "The Role of Self-Regulated Learning in Students' Success in Flipped Undergraduate Math Courses." Internet \& Higher Education 36: 41-53. doi:10.1016/j.iheduc.2017.09.003.

Tanner, Maureen, and Elsje Scott. 2015. "A Flipped Classroom Approach to Teaching Systems Analysis, Design and Implementation to Second Year Information Systems University Students." Journal of Information Technology Education: Research 14: 219-241. doi:10.28945/ 2266.

Teng, Mark Feng. 2017. "Flipping the Classroom and Tertiary Level EFL Students' Academic Performance and Satisfaction." Journal of Asia TEFL 14 (4): 605-620. doi:10.18823/asiatefl. 2017.14.4.2.605.

Thongmak, Mathupayas. 2019. “The Student Experience of Student-Centered Learning Methods: Comparing Gamification and Flipped Classroom.” Education for Information 35 (2): 99-127. doi:10.3233/EFI-180189.

Tomas, Louisa, Neus Snowy Evans, Tanya Doyle, and Keith Skamp. 2019. “Are First Year Students Ready for a Flipped Classroom? A Case for a Flipped Learning Continuum.” International Journal of Educational Technology in Higher Education 16 (1), doi:10.1186/s41239-019-0135-4.

Tonkin, Kati, Sara Page, and Martin Forsey. 2019. "Managing Cognitive Load with a Flipped Language Class: An Ethnographic Study of the Student Experience." Foreign Language Annals 52 (3): 551-575. doi:10.1111/flan.12412.

Torío, Herena. 2019. "Teaching as Coaching: Experiences with a Video-Based Flipped Classroom Combined with Project-Based Approach in Technology and Physics Higher Education." Journal of Technology and Science Education 9 (3): 404-419. doi:10.3926/JOTSE.554.

Tucker, Bill. 2012. “The Flipped Classroom.” Education Next 12 (1): 82-83. http://www. msuedtechsandbox.com/MAETELy2-2015/wp-content/uploads/2015/07/the_flipped_ classroom_article_2.pdf.

Turner, Mathew J., and Rustin D. Webster. 2017. "A Comparison of Delivery Formats to Encourage Student-Centered Learning in a Power Engineering Technology Course." American Journal of Engineering Education 8 (2): 141-156. doi:10.19030/ajee.v8i2.10071.

Turra, Héctor, Valeria Carrasco, Ciro González, Vicente Sandoval, and Soledad Yáñez. 2019. "Flipped Classroom Experiences and their Impact on Engineering Students' Attitudes towards University-Level Mathematics." Higher Education Pedagogies 4 (1): 136-155. doi:10. 1080/23752696.2019.1644963.

Urfa, Mehmet, and Gürhan Durak. 2017. "Implementation of the Flipped Classroom Model in the Scientific Ethics Course." Journal of Education and e-Learning Research 4 (3): 108-117.

van Vliet, Erwin A., Jacobus Cornelis Winnips, and Natasa Brouwer. 2015. "Flipped-Class Pedagogy Enhances Student Metacognition and Collaborative-Learning Strategies in Higher Education But Effect Does Not Persist." Cbe-Life Sciences Education 14 (3): 10. doi:10.1187/ cbe.14-09-0141.

Vercellotti, Mary Lou. 2018. "Do Interactive Learning Spaces Increase Student Achievement? A Comparison of Classroom Context." Active Learning in Higher Education 19 (3): 197-210. doi:10.1177/1469787417735606.

Vygotskij, Lev Semenovič. 1978. Mind in Society: The Development of Higher Psychological Processes. Cambridge, MA: Harvard University Press.

Wang, Jinghui, Dongshuo Wang, and Minjie Xing. 2019. "Flipped Classroom for Practical Skills to Enhance Employability: A Case Study of Business Chinese.” International Journal of ComputerAssisted Language Learning and Teaching 9 (1): 19-31. doi:10.4018/IJCALLT.2019010102. 
Wang, Kai, and Chang Zhu. 2019. "MOOC-Based Flipped Learning in Higher Education: Students' Participation, Experience and Learning Performance." International Journal of Educational Technology in Higher Education 16 (1), doi10.1186/s41239-019-0163-0.

Weaver, Gabriela C., and Hannah G. Sturtevant. 2015. "Design, Implementation, and Evaluation of a Flipped Format General Chemistry Course." Journal of Chemical Education 92 (9): 14371448. doi:10.1021/acs.jchemed.5b00316.

White, Paul J., Som Naidu, Elizabeth Yuriev, Jennifer L. Short, Jaqueline E. McLaughlin, and Ian C. Larson. 2017. "Student Engagement with a Flipped Classroom Teaching Design Affects Pharmacology Examination Performance in a Manner Dependent on Question Type." American Journal of Pharmaceutical Education 81 (9): 10-23. doi:10.5688/ajpe5931.

Williams, Belinda, Claire Horner, and Stephen Allen. 2019. "Flipped v's Traditional Teaching Perspectives in a First Year Accounting Unit: An Action Research Study." Accounting Education 28 (4): 333-352. doi:10.1080/09639284.2019.1609536.

Winberg, Christine, Hanelie Adendorff, Vivienne Bozalek, Honjiswa Conana, Nicola Pallitt, Karin Wolff, Thomas Olsson, and Torgny Roxå. 2019. "Learning to Teach STEM Disciplines in Higher Education: A Critical Review of the Literature." Teaching in Higher Education 24 (8): 930-947. doi:10.1080/13562517.2018.1517735.

Wood, Anna K., Ross K. Galloway, Christine Sinclair, and Judy Hardy. 2018. "Teacher-Student Discourse in Active Learning Lectures: Case Studies from Undergraduate Physics.” Teaching in Higher Education 23 (7): 818-834. doi:10.1080/13562517.2017.1421630.

Yamarik, Steven. 2019. "Flipping the Classroom and Student Learning Outcomes: Evidence from an International Economics Course.” International Review of Economics Education 31. doi:10. 1016/j.iree.2019.100163.

Yang, Qi-Fan, Chi-Jen Lin, and Gwo-Jen Hwang. 2019. "Research Focuses and Findings of Flipping Mathematics Classes: A Review of Journal Publications Based on the TechnologyEnhanced Learning Model.” Interactive Learning Environments. doi:10.1080/10494820.2019. 1637351.

Yao, Christina W., and Courtney Collins. 2018. "Perspectives from Graduate Students on Effective Teaching Methods: A Case Study from a Vietnamese Transnational University.” Journal of Further and Higher Education, 1-16. doi:10.1080/0309877X.2018.1429583.

Yong, Darryl, Rachel Levy, and Nancy Lape. 2015. "Why No Difference? A Controlled Flipped Classroom Study for an Introductory Differential Equations Course.” PRIMUS 25 (9): 907921. doi:10.1080/10511970.2015.1031307. 